\title{
EMOTIONAL INTELLIGENCE AND LEADERSHIP IN A SOUTH AFRICAN FINANCIAL SERVICES INSTITUTION
}

by

\begin{abstract}
ALISON JANE DU TOIT
submitted in accordance with the requirements

for the degree of
\end{abstract}

MASTER OF COMMERCE

in the subject

INDUSTRIAL AND ORGANISATIONAL PSYCHOLOGY

at the

UNIVERSITY OF SOUTH AFRICA

SUPERVISOR: PROF AM VIVIERS

JUNE 2014 


\section{FOR THE ATTENTION OF THE READER}

\section{SCOPE OF THE DISSERTATION}

For this master's dissertation of limited scope (50\% of the total master's degree), the Department of Industrial and Organisational Psychology prescribes an article format. This format involves four chapters - an introductory and literature chapter, followed by a research article (presented as chapter 3) and ending with a conclusion/limitations/recommendations chapter. For this dissertation, the Department recommends a boundary of approximately 60 to 80 pages.

\section{TECHNICAL AND REFERENCE STYLE}

In this dissertation, the researcher has chosen the publication guidelines of the South African Journal of Labour Relations to structure the dissertation and article. The Harvard style was therefore followed for the technical editing and referencing.

\section{DECLARATION}

I, Alison du Toit, student number 07940734, declare that

"Emotional intelligence and leadership in a South African financial services institution" is my own work, and that all the sources that I have used or have quoted from have been indicated and acknowledged by means of complete references. 


\section{ACKNOWLEDGEMENTS}

My gratitude needs to be expressed to the following people who have in unique ways shaped my journey and contributed to me achieving this immensely important milestone in my life:

- First and foremost to my Heavenly Father for bestowing me with many gifts and blessings. All the glory to Him.

- My husband, Anton, for your understanding and quiet support through this process.

- My beautiful children, Ashleigh, Damien, Dalton and Diemont for keeping me laughing and in touch with what it means to be a mother and role model for you.

- Henk Struwig, for being my friend and cheerleader and sending the messages I needed at the right time.

- Prof Adriaan Viviers, my supervisor, for your patience, feedback and support in the completion of this dissertation.

- Heidi Carter for being a remarkable role model and source of positive energy. You will forever be my guru.

- Michelle van der Mescht, two words: my lifesaver.

- To all my friends and colleagues whose kind words, encouragement and promises of bubbles have spurred me on. Bring on the bubbles!

- Nicola Taylor from Jopie van Rooyen and Partners for kindly answering all my questions and requests for additional information.

- Petra Gaylard for your statistical consultation and support. You have no idea how grateful I am.

- To my sisters, Kerry-Anne and Dayle who are my real and soul sisters, thank you for sometimes keeping me in check.

- And then last but certainly not least, to my parents Hilary and David Spence for believing in me and always letting me know how proud you are of me...I wish you had been here to share this with me. 
DECLARATION

ACKNOWLEDGEMENTS iii

LIST OF TABLES vii

LIST OF FIGURES vii

SUMMARY viii

CHAPTER 1: SCIENTIFIC ORIENTATION TO THE RESEARCH

1.1 BACKGROUND AND MOTIVATION 1

1.2 PROBLEM STATEMENT

1.2.2 Specific research questions 9

$\begin{array}{lll}1.3 & \text { AIMS } & 9\end{array}$

1.3.1 General aim of the research 9

$\begin{array}{ll}\text { 1.3.2 Specific aims of the research } & 10\end{array}$

1.4 THE PARADIGM PERSPECTIVE 10

$\begin{array}{ll}\text { 1.4.1 The relevant paradigms } & 10\end{array}$

1.4.1.1 Humanistic paradigm 10

1.4.1.2 Behaviourist paradigm 11

1.4.2 Methodological assumptions 12

1.4.2.1 Sociological dimension 12

1.4.2.2 Ontological dimension 12

1.4.2.3 Teleological dimension 13

1.4.2.4 Epistemological dimension 13

1.4.2.5 Methodological dimension 13

1.4.3 The central hypothesis 14

$\begin{array}{lll}1.5 & \text { RESEARCH DESIGN } & 14\end{array}$

$\begin{array}{ll}1.5 .1 \text { Research approach } & 14\end{array}$ 
1.5.2 Research method 14

1.5.2.1 Research participants 15

1.5.2.2 Measuring instruments $\quad 15$

1.5.2.3 Research procedure 16

1.5.2.4 Statistical analysis 17

1.6 CHAPTER LAYOUT 17

$\begin{array}{lll}1.7 & \text { CHAPTER SUMMARY } & 17\end{array}$

\section{CHAPTER 2: LITERATURE REVIEW}

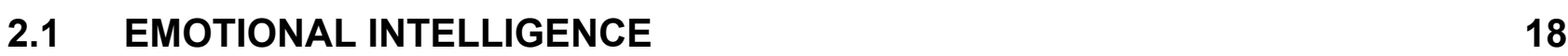

2.1.1 Definition and concept clarification of emotional intelligence 19

2.1.2 Emotional intelligence theories 20

2.1.2.1 The El ability-based model (Mayer \& Salovey, 1997) 21

2.1.2.2 Goleman's mixed model of emotional intelligence 21

2.1.2.3 Bar-On's emotional-social intelligence model (Bar-On, 1997; Bar-On, 2000) 22

2.1.3 The legitimacy of emotional intelligence 29

$\begin{array}{lll}2.2 & \mathbf{3 0}\end{array}$

2.2.1 The conceptualisation of leadership 31

2.2.1.1 The born leader (1920s to 1940s) 32

2.2.1.2 The grown leader(1940s to 1980s) 32

2.2.1.3 The conscious leader (1990s to present) 33

2.2.2 Shared, collective or distributed leadership 33

2.2.2.1 Leadership as a contextually embedded construct 34

2.2.2.2 Strategic leadership 35

2.2.2.3 Leadership as a non-hierarchical process 36

2.2.2.4 Values-based leadership 37

2.2.2.5 Leadership as a systemic construct 39

$\begin{array}{ll}2.2 .3 & \text { The organisation multi-rater }\end{array}$

2.2.3.1 Be strategic and visionary (STRT)

2.2.3.2 Demonstrate innovative, authentic values-based leadership (VBL) 41

2.2.3.3 Design organisational systems \& process (OD) 41 
2.2.3.4 Embrace diversity and transformation (DIV)

2.2.3.5 Focus on delivery and execution (DEL)

2.3 INTEGRATION OF EMOTIONAL INTELLIGENCE AND LEADERSHIP

CHAPTER 3 : RESEARCH ARTICLE

CHAPTER 4 : CONCLUSIONS, LIMITATIONS AND RECOMMENDATIONS

\subsection{CONCLUSIONS}

4.1.1 Literature review

4.1.2 Empirical study

4.2 LIMITATIONS 85

4.2.1 Literature review 86

4.2.2 Empirical study 86

4.3 RECOMMENDATIONS 87

4.4 CHAPTER SUMMARY 89 


\section{LIST OF TABLES}

Table 1: Sample characteristics

Table 2: Descriptive analysis for the EQi

Table 3: Descriptive analysis for the leadership multi-rater

Table 4: Intercorrelations for the emotional intelligence dimensions of the EQi and the leadership dimensions of the multi-rater

Table 5: Results of forward selection multiple regression analysis with the leadership dimensions overall leadership, strategy, values-based leadership, organisational design, diversity, delivery and citizenship as dependent variables and emotional intelligence subscales as the independent variables

\section{LIST OF FIGURES}

Figure 1: Bar-On's model of emotional intelligence 


\title{
SUMMARY
}

\section{TITLE OF DISSERTATION}

Emotional intelligence and leadership in a South African financial services institution

\author{
AUTHOR \\ Alison du Toit
}

DEGREE

Master of Commerce in Industrial and Organisational Psychology

\section{UNIVERSITY}

University of South Africa, Pretoria, South Africa

The purpose of this study was to determine whether there is a relationship between emotional intelligence and leadership among senior leaders in a South African financial services organisation. The sample consisted of 973 participants. A convenience sample was used, as the leaders were part of a strategic organisational initiative and completed measurement instruments as part of this process. All participants completed the Bar-On EQ-i, in order to measure emotional intelligence, whereas the leadership data were obtained from an organisation-specific multi-rater which accessed self-ratings, peer and subordinate ratings as well as manager ratings in terms of leadership behaviours linked to organisational worldviews of leadership effectiveness. The results show that there was a statistically significant relationship between emotional intelligence and leadership among the leaders, but that there was poor predictive strength between these variables.

KEY TERMS: emotional intelligence, leadership, banking institution, senior leaders 


\section{CHAPTER 1: SCIENTIFIC ORIENTATION TO THE RESEARCH}

This dissertation focused on the relationship between emotional intelligence and leadership in a South African financial services institution. Chapter 1 contains the background and motivation, the problem statement, the aims, paradigm perspective, research design and method as well as the chapter layout.

\subsection{BACKGROUND TO AND MOTIVATION FOR THE RESEARCH}

"Never before in the course of human evolution have we had the opportunity and the responsibility to make conscious choices with so much knowledge and information at our finger tips. We are at an important turning point in the world. This requires awareness and a new way of thinking, feeling and acting individually and together. This demands a different type of leadership that can bring about fundamental and profound change through informed, wise and courageous choices. New leadership wisdom that transcends the reliance on individual 'hero' leaders is called for" (Carter 2009:1).

A culture of global consumption and consumerism is continuously exerting pressure on our planet's resources. The world is confronted with challenging global health issues and escalating disparities in wealth between the rich and the poor. Human beings are increasingly inundated with images of chaos and crisis in our everchanging world. The irony is that although there is such intense fragmentation and polarisation, global citizens are living in a time where the environment and humanity as a whole are increasingly interdependent and wholly connected (Carter \& Nussbaum 2010; De Bettignies \& Lépineux 2009; Glenn, Gordon \& Florescu 2010). The global financial market crisis of 2008 and subsequent Transatlantic banking crisis demonstrated this reality of our world as an interconnected system. Around the world, stock markets have fallen, large financial institutions have collapsed or been bought out, and governments in even the wealthiest nations have had to come up with rescue packages to bail out their financial systems (Welfens 2009, 2011). South African organisations, as part of the international community, are also confronted 
with these challenges and a period of transition (Chauhan 2012). These complexities increase the pressure on organisations and leadership to perform and place a tremendous focus on the need to manage the blurring of boundaries (Cascio 2001; Gitsham \& Pegg 2012; Leslie \& Canwell 2010). How do organisations and leaders manage the paradoxes, cope with these complexities and stay connected to that which is important for sustained business success? The expectations of leaders today are unrealistic and loaded with projections of individual power, prestige and salvation (Kellerman 2012; Struwig 2012).

The South African financial services organisation, on which this study is based, is a bank employing 27000 people and operating as one of the four largest banking groups in South Africa. From 1995, the organisation outperformed the market and was the most highly rated bank in the late 1990s. But by 2001, a downward trend started to emerge when judgment calls and investment decisions began to unravel. Several strategic management decisions highlighted the thinking of the era, and the focus was on the top end of the market, and by closing down branches the organisation dismissed lower-end consumers. The bankhit rock bottom in 2003. The harsh reality which shocked the investment community and staff included a shortage of capital, an incorrect reading of interest rates and too much capital invested overseas. There was a major loss of credibility, the investment community and staff no longer trusted management, and the organisation was at risk of being shut down (Financial Mail 2006; Leadership Magazine 2009).

A new CEO was appointed in 2003 along with a new executive team (Financial Mail 2006). The burning platform was obvious. Striving to become the biggest and most profitable bank was not the goal. Instead, management wanted the bank to become the most respected and highly rated in the country and a culture dominated by costs had to be shifted to one driven by clients. However, staff morale was at an all-time low. The executive realised that they required a series of interventions for cultural transformation within a broader business transformation programme, which would allow them to move the minds and energy of staff towards a new vision and enable them to deliver to their clients (Carter 2010; Financial Mail 2006). One of the central 
assumptions that informed the conceptual approach to the transformation programme was the CEO's belief that making the company a great place to work, would also make it a great place to bank (www.valuescentre.com). In enabling this, the CEO felt strongly that a vision and a set of values had to be determined before staff could be drawn into what would become a challenging transformation process. $\mathrm{He}$ took his guiding mantras from the original conception of Richard Barrett, "Liberating the Corporate Soul," published in 1998, upon which this organisational research was based (www.valuescentre.com). These guiding principles are as follows: Firstly, the most successful organisations on the planet are vision guided and values driven. In the CEO's analysis, this places an important requirement on the leaders of the organisation. Secondly, organisations do not transform, people do and consequently core to the organisation's business transformation must be a process that promotes personal transformation, starting with the leadership group. With this philosophy as a cornerstone, the executive commissioned a large-scale transformation journey integrating strategy, values-based leadership and diversity in June 2005 (Carter 2010; Financial Mail 2006; www.valuescentre.com). The data for this research was drawn from the values-based leadership component of the process.

According to De Miranda (2011), many leadership theories today indicate that leadership is transforming at a rapid pace to keep up with globalisation and flattening organisational hierarchies. Leaders operating in such a turbulent environment are required to possess a specific set of skills. Historically, leadership models emphasised hierarchy, charisma and power over followers (Avolio, Walumbwa \& Weber 2009). In contrast, new models emphasise collaboration, shared power, and recognition of multiple leadership styles and roles (Block 2012; Hamel \& Breen 2007; Kellerman 2012; Mintzberg 2009). New models also increasingly emphasise emotional over technical intelligence (Goleman, Boyatzis \& McKee 2002). Although leadership studies in the past focused almost exclusively on leaders with formal authority, the idea of leadership roles of individuals with little or no authority is gaining more ground (Block 2008; Mintzberg 2009). It is the leadership definition of the classic resource Rost (1993:102) as "an influence relationship among leaders 
and followers who intend real changes that reflect their mutual purposes" which the organisation included in this research and used as a seminal work.

Where do organisations look to in their search to develop effective leaders? Bar-On (1997) questioned why some people possess greater emotional well-being? Why some are better able to achieve success in life? And, most importantly, why do some people who are blessed with high levels of intellectual ability seem to fail in life, while others with more modest intellectual capacity succeed? Rosete and Ciarrochi (2005) imply that leaders perhaps need emotional intelligence (EI) (measured by the emotional quotient (EQ)) as opposed to cognitive intelligence or specific personality traits to be successful. Similarly, Barrett $(1998,2006)$ is clear on the point that individual and organisational growth and development are directly linked to the extent to which individuals are willing to face up to the emotional issues that separate them from their souls. "Self-knowledge at a personal and organisational level is the only pathway to evolution and growth" (Barrett 1998:9).

Leadership has been described as the competencies and practices required to enable and empower ordinary people to do extraordinary things in the face of adversity. It is also the ability to constantly deliver higher performance to the benefit of the individual and the organisation. These definitions include being skilled in emotional competencies (Stuart \& Paquet 2001). In this context it would seem that evaluation of leadership from an organisational, group or dyadic perspective would be insignificant, given that the questions raised presuppose that it is an intrinsic differentiation that needs investigation. This is supported by the growing acknowledgement that emotions play a critical role in both the leader's effectiveness and business success (Anand 2010; Freedman \& Everett 2010; Goleman 1995, 1998; Goleman et al. 2002; Higgs 2003).

Emotional intelligence as a broad construct addresses the emotional, personal, social and survival dimensions of intelligence, which are emerging as considerably more important for daily functioning than the more traditional cognitive aspects of intelligence. Emotional intelligence underpins understanding one's self and others, 
the interpersonal relationship space and the ability to adapt to and cope with environmental demands (Anand 2010; Stuart \& Paquet 2001). According to the seminal work of Salovey and Mayer (1990), emotions are fundamentally driving forces that arouse, direct and sustain activity. Hence emotional life can be managed with greater or lesser skill and requires a unique set of competencies. Emotional intelligence is an essential aspect in determining one's ability to succeed in life and is understood to directly influence one's state of mind or overall degree of emotional health (Bar-On 1997). Based on these insights, Stuart and Paquet (2001:30) postulate that "emotional health should also have some impact on the presence or absence of leadership ability".

According to the programme director working in the organisation, within the valuesbased leadership component of the organisation's transformation journey, the executive identified the imperative to develop a personal transformation approach, the core of which was the capacity for emotionally intelligent functioning (Carter 2010). Linking to the work of Barrett (1998), Goleman (1995, 1998) and Bar-On (1997) that demonstrates this, EQ was seen to be a key factor to include in the transformation process aimed at leaders. It was felt that without the capacity for interdependence, individuals would not be ready for the collaborative and participative effort required to turn the organisation around. EQ was seen to be at the core of rebuilding and restabilising the social fabric and psychological climate of the organisation. It was felt that a safe psychological climate in which people feel comfortable to question practices, admit mistakes and voice dissonance would be an important contributor to the effectiveness of leadership in that organisation (Hofmann, Morgeson \& Gerras 2003). EQ was seen as significant in complementing and balancing what had become a predominantly numbers and task-driven focus. The organisation referred to in this study was acutely aware, as an organisation in the throes of a critical turnaround process, that there had been a blinkered focus on the numbers and that the viability of the business was dependent on making a significant financial shift. Once out of the red and in moving to a more sustainable strategy inclusive of its emerging worldviews, it was crucial that the organisation concentrate on shifting its focus towards incorporating a more human and emotional 
element within its leadership capability. The decision to bring emotional intelligence into the area of leadership development was introduced to specifically support the transition from a mindset focusing on numbers and $I Q$ to a mindset including humanism, heart, EQ and essentially a whole person approach (Carter 2009; Financial Mail 2006; www.valuescentre.com).

The traditional approaches to leadership emphasise an individual-focused, leadercentric, dyadic and small group view, which is a meso/micro perspective. Subsequently, the focus has been on behaviours manifesting in the leader-follower relationship and not on the strategic responsibilities of leadership in shaping a strategy that provides an architecture enabling the organisation to grow and flourish in a dynamic environment. Essentially the macro and contextual aspects of leadership have been given little attention (Avolio 2007; Crossan, Vera \& Nanjad 2008). Carter (2009) was clear that the organisation could not look at the effectiveness of its leaders as separate from their context, given the bleak reality of financial survival, and the organisation thus needed to understand that leadership effectiveness is moderated by the dynamics of the context and the environment. Hence the paradigm adopted by the organisation builds on the traditional models of leadership to include a more integrated, holistic and multi-level approach to leadership. These levels acknowledge intrapersonal, interpersonal, organisational and societal implications for leadership.

The context for the organisation being reviewed in this research was whole-scale systemic change, that is, a long-term, cross-functional change. Thus leadership behaviour was about influencing members of a societal system along with an organisational system to be enrolled in the new strategic vision and direction of the business. Given that the organisation viewed leadership as an embedded construct, there was a clear understanding that a shift in its context, and the threat of business survival, both nationally and internationally required a change in leadership which inversely meant that an act of leadership would reconstitute the context to varying degrees (Carter 2009; www.valuescentre.com). 
The thinking behind the leadership development process as part of the overall transformation process was to work towards creating a tipping point (Gladwell 2002), where a critical mass is reached which can change the system significantly and fundamentally, that is a change in behaviour of 1800 leaders, which would then shift the organisational culture. The organisational transformation needed to be based in the personal transformation of a community of 1800 leaders with a focus on personal mastery through emotional intelligence development, leadership effectiveness through enhanced interdependence, improved relational capacity and a group-wide mindset. It was intentionally designed to be a shared process of mutual reciprocity and not about being leadercentric (Carter 2010).

While there are various studies that provide empirical evidence that emotional intelligence has a positive effect on leadership effectiveness, as well as popular leadership gurus who support the role of EQ on leadership effectiveness (Kerr, Garvin, Heaton \& Boyle 2006; Collins 2001; Drucker 1999; Goleman 1995, 1998; Leban \& Zulauf 2004; Ruderman, Hannum, Leslie \& Steed 2001; Van Oosten 2013), studies also reflect that emotional intelligence has no statistical significance in leadership effectiveness (Antonakis 2004; Barbuto \& Burbach 2006; Brown, Bryant \& Reilly 2006). However, the above-mentioned studies were conducted predominantly in an international arena and their relevance and applicability in the South African context, specifically in the field of financial services pertinent to the organisation under review, needs further investigation to truly understand the dynamics at play and whether there is a justifiable place for emotional intelligence in the development of leadership capacity towards increased effectiveness. If a relationship between emotional intelligence and leadership could be found, the results could be used by the organisation for leadership development purposes.

\subsection{PROBLEM STATEMENT}

From a humanistic perspective it would seem evident that any research, which may shed light on the growth and strengthening of leadership capacity, which in turn could impact on effectiveness, would be meaningful and welcome. The long history 
of leadership research has, according to Kets de Vries (1993, 2001), unsuccessfully provided any clear or consistent insight into the nature of leadership and the requirements of an effective leader. Questions still linger around why intelligent and seasoned leaders are not always successful in managing and coping with environmental demands and life in general (Brackett, Rivers \& Salovey 2011; Mills 2009; Rosete \& Ciarrochi 2005).

Studies have also been conducted in a South African context (Astrup \& McArthur 2011; Coetzee \& Schaap 2005; Ramchunder \& Martins 2014; Stuart \& Paquet 2001; Vrba 2007) in order to explore the relationship between emotional intelligence and leadership, and the conclusion drawn was that emotional intelligence relates significantly to leadership behaviour and the outcomes of leadership that are considered either effective or ineffective in a rapidly changing environment. However, given the levels of interest in the subject and the amount of vested interest organisations have in developing a resilient, sustainable and effective leadership capacity, there does not seem to be sufficient practical research in this field and certainly not in South Africa specifically. When taking into consideration the potential contribution of emotional intelligence to the scientific and applied fields of industrial psychology in a South African context, as well as its possible value in leveraging the development of leadership, it becomes evident that research into the relationship of these variables is certainly meaningful to pursue. The increase in knowledge and research will broaden the field of Industrial and Organisational psychology especially with respect to the financial services industry thereby enabling a better understanding of the leverages required to develop leadership and understand the nature of enhancing leadership effectiveness. Hence the test for the organisation is to uncover the relationship between emotional intelligence and the manifestation of leadership in order to understand the value of this relationship and its implications for leadership development.

To address the above issues, this research was designed to answer the literature and empirical questions in the next section. The general research question that required further investigation was as follows: Is there a positive and significant 
relationship between the level of emotional intelligence and leadership in leaders in a South African financial services institution and furthermore, does emotional intelligence serve as a predictor of effective leadership?

\subsubsection{Specific research questions}

With respect to the literature review the following specific research questions were addressed in this research project:

- Research question 1: How is emotional intelligence conceptualised?

- Research question 2: How can leadership be conceptualised in the specific organisational context?

- Research question 3: Is there a relationship between emotional intelligence and leadership?

With respect to the empirical study, the following specific research questions were addressed in this research project:

- Research question 1: What is the empirical relationship between emotional intelligence and leadership?

- Research question 2: Can emotional intelligence and its components predict effectiveness in leadership?

\section{$1.3 \quad$ AIMS}

\subsubsection{General aim of the research}

With reference to the above-mentioned problem statement and research questions, the general aim of this research was to determine the nature of the relationship between the emotional intelligence and leadership of senior leaders in a South African financial services institution. 


\subsubsection{Specific aims of the research}

In terms of the literature review, the following specific aims were formulated:

- Research aim 1: To conceptualise the construct of emotional intelligence

- Research aim 2: To conceptualise leadership from an organisational perspective

- Research aim 3: To determine the theoretical relationship between emotional intelligence and leadership

In terms of the empirical study, the following specific aims were formulated:

- Research aim 1: To determine the relationship between emotional intelligence and leadership

- Research aim 2: To establish whether emotional intelligence and its components can be viewed as a predictor of leadership

- Research aim 3: To formulate recommendations on the basis of the research findings and to stimulate future research

\subsection{THE PARADIGM PERSPECTIVE}

In understanding the paradigm perspective of this research, the relevant paradigms, meta-theoretical concepts and methodological assumptions will now be explored. The word paradigm, according to Guba (1990), is used in multiple forms in social scientific literature. The concept refers to the most basic set of beliefs and assumptions. It refers to the frame of reference that leads to the actions of scientific enquiry. It is regarded as the intellectual climate of scientific enquiry (Guba 1990).

\subsubsection{The relevant paradigms}

\subsubsection{Humanistic paradigm}

Emotional intelligence in this research was presented from a humanistic paradigm perspective. According to this perspective, everyone has the potential to grow and develop and therefore assessing one's emotional intelligence and understanding the 
implications affords one the opportunity for self-growth and understanding of self in relation to others (Meyer, Moore \& Viljoen 2003). According to Ivey, Ivey and SimekMorgan (1997), the combination of individual respect and the importance of relationships are what ensure the sustainability and longevity of the humanistic framework.

The applicable assumptions of the humanistic paradigm are as follows (McLeod 2003):

- It is an approach not solely grounded in psychology, but draws significantly from other fields of humanism including literature, the arts and philosophy.

- There is an emphasis on optimal functioning as opposed to pathology.

- The person is conceptualised as an individual "self".

- There is a reliance on a loosely connected network of ideas as opposed to employing a single, clear theoretical focus.

- There is a sense of a set of ideas and practices that through their existence challenge the mainstream, that find their distinctiveness through not being psychoanalysis or behaviourism, rather than representing a positive alternative that might seek to replace them.

\subsubsection{Behaviourist paradigm}

Leadership presented in this research was studied primarily from the behaviourist paradigm. Meyer et al. (2003) present behaviourism as a learning theory that only focuses on objectively observable behaviours and discounts any independent activities of the mind. Behaviour theorists define learning as nothing more than the acquisition of new behaviour based on environmental conditions. Thus the thrust of behaviourism is behavioural change.

The applicable assumptions are listed below (Meyer et al. 2003):

- Behaviourism adopts a positivist (authentic knowledge) and empiricist (perceived using the sensory experience) perspective, and observable behaviour is therefore the object of study. 
- It accepts that objective, sensory perception is the only reliable method of accumulating knowledge and thus deemed entirely objective.

- Behaviour is viewed as essentially consisting of two elements, namely stimuli and responses, which are combined through the organism's learning experiences.

- Behaviourism is concerned with finding out what dynamics determine human behaviour, the goal being to use this knowledge to predict and control human behaviour.

\subsubsection{Methodological assumptions}

Methodological assumptions are beliefs concerning the nature of social science and scientific research. The research model of Mouton and Marais (1991) served as a framework in this research. Its intent is to incorporate the five dimensions of social science research (sociological, ontological, teleological, epistemological and methodological) and operationalise them in the framework of the research process.

\subsubsection{Sociological dimension}

The sociological dimension emphasises that scientists operate within a clearly defined community, a context with similar psychic boundaries and linked in research networks that form the basis for future research (Mouton \& Marais 1991). This research centered on the quantitative analysis of variables, and made use of research networks through the examination of various scientific publications.

\subsubsection{Ontological dimension}

The ontological dimension of research embraces the study of being or reality that is measured. It relates to the study of human activities and institutions whose behaviour can be measured (Mouton \& Marais 1991). This research focused on the measurement of emotional intelligence and leadership constructs. The research looked at the individual as a leader and investigated the role of emotional intelligence in leadership capacity. 


\subsubsection{Teleological dimension}

This dimension refers to the fact that social science is goal driven, with practical and theoretical research outcomes or goals. Through knowledge acquisition, reality can and must be changed (Mouton \& Marais 1991). The goals of this research were explicit, namely to determine the relationship between emotional intelligence and leadership in a specific organisational context. Furthermore, this dimension practically looks to furthering the field of industrial and organisational psychology by expanding the body of knowledge, thereby enabling an individual to function optimally in an organisation.

\subsubsection{Epistemological dimension}

The epistemic ideal embraced in this dimension relates to the search for truth, indicating that the aim of research is to generate valid findings which approximate reality as closely as possible (Mouton \& Marais 1991). This research attempted to realise this dimension through a sound research design and the achievement of valid and reliable results.

\subsubsection{Methodological dimension}

This dimension relates to the logic of the application of scientific methods to the investigation of phenomena, that is, the beliefs concerning the nature of social science and scientific research. The three general methodological approaches are the quantitative, qualitative and participatory action approaches (Mouton \& Marais 1991). Quantitative or explanatory research was presented in the empirical study in the form of data collection through questionnaires, data analysis through statistical analysis and finally inference through inductive reasoning. 


\subsubsection{The central hypothesis}

The central hypothesis of the research can be formulated as follows:

There is a positive and significant relationship between emotional intelligence and leadership among leaders in the financial services organisation.

\subsection{RESEARCH DESIGN}

According to Mouton and Marais (1991), the aim of research design is to plan and structure a given research project in such a way that the external and internal validity of the research findings is maximised. The design is thus the outline, plan or strategy, which delineates the procedure to be used in seeking an answer to the research question (Babbie \& Mouton 2009).

The structure of the research design is highlighted below. The design is presented according to the research approach and method used.

\subsubsection{Research approach}

The empirical study followed a non-experimental research design to determine the relationship between emotional intelligence and leadership. A quantitative approach to the study was proposed with a cross-sectional survey design being followed. Surveys are mainly used in studies that have individual people as units of analysis (Babbie \& Mouton 2009). The responses were collected by means of convenience sampling. The use of an electronic survey methodology ensured that the leaders' responses were captured at a single point and time (Babbie \& Mouton 2009).

\subsubsection{Research method}

The research participants, measuring instruments, research procedure and statistical analysis are set out and discussed below. 


\subsubsection{Research participants}

According to Babbie and Mouton (2009), the unit of analysis is the individuals or things and characteristics which researchers are curious about observing, describing and explaining. When the unit of analysis is the individual, the researcher focuses on the characteristics and the orientations of individual behaviour. The unit of analysis for the purposes of this research was the individual, namely male and female leaders. This research project was conducted in a South African financial services institution, employing a total of 27000 employees. The participants in this study consisted of executive and senior-level management $(n=1800)$ across all business units who were strategically identified based on the scope, capacity and budget linked into the afore-mentioned organisational leadership development programme. This population $(n=1800)$ represented a non-random sample of convenience, of which the final sample was 973 respondents $(n=973)$.

\subsubsection{Measuring instruments}

The measuring instruments utilised in the overall leadership development programme in the organisation and thus which formed the basis for this research were the Bar-On emotional-social intelligence model (EQ-i) (Bar-On 1997) and the 360-degree leadership assessment instrument designed specifically for the organisation, namely the organisation multi-rater.

The Bar-On emotional quotient inventory (EQ-I) is a self-report measure designed to measure a number of constructs related to emotional intelligence (Bar-On 2006). It does not measure personality traits or cognitive capacity, but instead the mental ability to be successful in managing environmental demands and stresses. The internal consistencies for the 15 subscales range between 0.69 and 0.86 with an overall average internal consistency of 0.76 (Bar-On 1997). 
The organisation multi-rater was used to assess leadership. This is a customised 360-degree assessment that focuses on six leadership themes and five values as the measured dimensions and includes 59 items. After testing reliability following an iterative process the data stabilised at a Cronbach alpha reliability of 0.97 .

\subsubsection{Research procedure}

This study did not involve primary data collection. Because the organisational leadership development programme initiated the data collation, this existing data was used for comparative analysis and study. Written permission was granted by the CEO of the organisation to make use of the data and include it in this study.

During the initial data collection process, the procedure was as follows:

- A communication was sent to all participants by their business unit heads outlining the overall programme, its purpose and rationale.

- An e-mail was then sent to all participants as an invitation to participate. This e-mail explained the process of the self-assessment aspect of the two questionnaires as well as the nomination of raters for the multi-rater.

- Each participant was asked to register using a link for the service provider used for the electronic administration of the questionnaires to ensure complete confidentiality.

- Each participant was given a unique registration code to ensure the tracking of all his/her specific feedback.

- The participants were then asked to nominate raters for the multi-rater assessment of which one needed to be their manager and the other eight divided equally between peers and direct reports.

- Assessment required the following two levels: (1) the respondent had to assess himself/herself on both measuring instruments; and (2) the respondent had to be assessed by nine raters (manager, peers/colleagues and direct reports/subordinates) on the multi-rater instrument.

- A project support team outside the organisation was used to track and monitor participant and rater completion. This was all done electronically. 


\subsubsection{Statistical analysis}

A number of statistical techniques were used to investigate various dimensions of the data.

The Cronbach alpha was calculated to determine internal consistency and descriptive statistics were used to describe the sample. Correlations were calculated to investigate the positive or negative nature of the relationship between the independent and dependent variables. Both forward and backward stepwise regression analysis was performed to select the best subset of independent variables for each dependent variable to explore the relationship between emotional intelligence and leadership.

\subsection{CHAPTER LAYOUT}

The layout of the remaining chapters is as follows:

Chapter 2 Literature review

Chapter 3 Article

Chapter 4 Conclusions, limitations and recommendations

\subsection{CHAPTER SUMMARY}

In chapter 1, the scientific orientation to the research was discussed. This dealt with the background and motivation, the research problem, the aims, the paradigm perspective and the research design. The chapter ended with the chapter layout. 


\section{CHAPTER 2: LITERATURE REVIEW}

This chapter contains the literature review on emotional intelligence and leadership. Thereafter the literature is integrated towards formulating the central theoretical statement to be explored in the empirical study.

\subsection{EMOTIONAL INTELLIGENCE}

Over the past century, cognitive intelligence has been the departure point of understanding an individual's functioning capability, cognitive capacity and a predictor of potential. However, there was an exploration of characteristics other than intelligence which could satisfactorily explain variations in an individual's success (Bar-On 2010).

In the 1980s, Dr Reuven Bar-On, had been asking questions around the differentiators for psychological well-being and success. The first experimental phase of Bar-On's research was conducted between 1983 and 1986 in South Africa, at Rhodes University, as part of his doctoral studies where the phrase 'emotional quotient' (EQ) emerged as a measure of emotional (Stein \& Book 2006). The Bar-On EQ-i instrument, which will be discussed in more detail later, was a product of a "theoretically eclectic and multifactorial approach to operationally defining and quantitatively describing emotional intelligence" (Bar-On 1997:1). It became evident that in this era there was a shift towards gaining an understanding of how emotion and thought influence each other (Bar-On 2005; Mayer 2001).

With the publishing of Daniel Goleman's book, Emotional intelligence: why it can matter more than IQ, in 1995, the concept of $E Q$ and the contribution it makes in our lives was catapulted into the public arena. According to Stein and Book (2006), Goleman managed to demystify years of research into psychological functioning and interpersonal skills, and translate it in an accessible and engaging manner that a layperson could grasp. However, there is a sense that these lay publications threatened to erode confidence in the core concept of El with oversimplification of the concept, expansive promises, one-sided arguments and expectations of results 
superseding the scientific data available to them (Fernández-Berrocal \& Extremera 2006; Stein \& Book 2006). In recent times, the application implications for the organisational context have been emerging, with strongly motivated research and case studies which build a case for how emotional intelligence contributes to the bottom line in any work organisation (Boyatzis 2009; Cavallo \& Brienza 2000; Chaudhry \& Saif 2012; Matthews, Roberts \& Zeidner 2004).

\subsubsection{Definition and concept clarification of emotional intelligence}

There seems to be robust debate surrounding what exactly the definition of emotional intelligence should comprise. Dulewicz and Higgs (2000) highlight this general lack of consensus around the composition of the concept by referring to the confusing range of varyingly related terminologies, including emotional intelligence (e.g. Goleman 1996; Salovey \& Mayer 1990), emotional literacy (e.g. Steiner 1997), emotional quotient (e.g. Bar-On 1997; Goleman 1996, 1997), personal intelligences (e.g. Gardner 1983), social intelligences (e.g. Thorndike 1920) and interpersonal intelligence (e.g. Gardner \& Hatch 1989). Locke (2005) even goes so far as to argue that $\mathrm{El}$ is an invalid concept, in part because it is defined in too many ways.

There are currently three theoretical approaches that dominate this field and they are widely accepted and challenged by the scientific community while informing current lines of research. According to Fernández-Berrocal and Extremera (2006), they attempt to discover the emotional components that lie beneath emotionally intelligent people and the dynamics and processes that engage these abilities in our daily lives. Each theoretical paradigm conceptualises emotional intelligence from one or two perspectives: ability or a mixed model. These approaches and definitions will be further expounded on in the sections that follow. The models will be briefly highlighted, but for the purposes of this study, they will not all be explored as BarOn's emotional-social intelligence model forms a central part of this research. 


\subsubsection{Emotional intelligence theories}

Evidently there are both mental ability models and mixed models of emotional intelligence. The mental ability model of Mayer and Salovey (1997) focuses on emotions themselves and their engagement with thoughts. The mixed models represented by Bar-On (1997) and Goleman (1995) treat mental abilities and a diversity of other characteristics as mutually exclusive.

According to Goleman (2001), despite the existence of these three distinct models of emotional intelligence, there are theoretical and statistical similarities between the various conceptions. At a universal level, all of the models aim to identify, understand and measure the essentials involved in the recognition and regulation of one's own emotions and the emotions of others. However, Mayer (2001) contends that the theoretical differences between the ability-based and mixed model approaches to emotional intelligence are pronounced. While the mixed model approaches have prospective value because of their exploration of multiple aspects of personality at one time, they are not specifically related to any new concept of emotional intelligence.

According to Matthews, Zeidner and Roberts (2002), the above fractions are not unusual or unexpected in an embryonic concept, which is still somewhat underexposed to empirical research. The fundamental challenge in developing conceptualisations of emotional intelligence is due to the established understanding of emotional functioning as it realtes to intelligence and personality traits (Matthews et al. 2002). There are clearly virtues and drawbacks in both the mixed model and ability approaches with further exploration and research required to bring greater insight to this debate. 


\subsubsection{The El ability-based model (Mayer \& Salovey 1997)}

Within the ambit of an ability model, emotional intelligence is considered to be a pure form of mental ability and thus a pure intelligence (Mayer 1999). These abilities were arranged hierarchically from basic psychological processes to the more psychologically integrated and complex and were thought to develop with age and experience. Salovey and Mayer made the first published attempt toward a definition of El in 1990. Their research continued and the definition of El was revised to "The ability to perceive emotion, integrate emotion to facilitate thought, understand emotions, and to regulate emotions to promote personal growth." (Mayer \& Salovey 1997:5).

The only ability model of emotional intelligence is that proposed by Mayer and Salovey (1997) which views emotions as useful sources of information that help one to make sense of and engage successfully with the social environment. The model has undergone continual improvement since its construction and Caruso, Mayer and Salovey (2002) offer the most updated version. The MSCEIT (Mayer-SaloveyCaruso emotional intelligence test) was developed with the focus on ability measures and is validated in many scientific publications (Stein \& Book 2006). Mayer and Salovey's mental ability model is the theoretical approach, which if El literature is to be reviewed, garners the most interest and review. Even the critics consider the model a genuine approach to the study of intelligence that could make significant contributions to the emotional individual differences field (Matthews et al. 2002).

\subsubsection{Goleman's mixed model of emotional intelligence}

The mixed models of emotional intelligence combine mental ability with personality characteristics such as optimism and well-being (Mayer 1999). Daniel Goleman proposed a mixed model in terms of performance, integrating an individual's abilities and personality and applying their corresponding effects on performance in the workplace (Goleman 2001). The work of Salovey and Mayer in the 1990s inspired Goleman to explore his own research in the field (Goleman 1995).According to 
Hamish Elliott in the Otago Management Graduate Review, Goleman provides the first concrete and authoritative fusion of emotional intelligence and the organisation (Elliott 2003).

Goleman's model (Goleman 2001) currently outlines the following four main emotional intelligence constructs: self-awareness, self-management, social awareness and relationship management (Goleman 2001). Goleman (1998) posits that human beings are born with a general emotional intelligence that is a determining factor in their potential for learning emotional competencies. Several measurement tools have been developed based on Goleman's model of emotional intelligence and its corresponding competencies. Included among these are the emotional competency inventory (ECI) (Boyatzis 1994; Boyatzis, Goleman \& Rhee 1999) and the emotional intelligence appraisal (EIA) (Bradberry \& Greaves 2003).

\subsubsection{Bar-On's emotional-social intelligence model (Bar-On 1997; Bar-On 2000)}

For the aim of this research, the researcher examined the emotional intelligence constructs as set out by Reuven Bar-On. The development of Bar-On's model was influenced by the likes of Darwin, with his work on the significance of emotional expressions for survival, Thorndike's social intelligence concept, Wechsler's work on non-cognitive intelligence as well as Gardner's interpersonal and intrapersonal intelligence (Bar-On 2007). Bar-On (1997) has put forth a model based in the context of personality theory, emphasising the co-dependence of the ability aspects of emotional intelligence with personality traits and their application to personal wellbeing. It was one of the first measures of emotional intelligence that used the term "emotion quotient". His approach to El was broader than Mayer and Salovey's (1997) model. One of his preliminary motivations was to discover the key factors and components of emotional and social functioning that could guide individuals to better psychological well-being. His non-cognitive model more generically referred to emotional intelligence as "an array of non-cognitive capabilities, competencies and 
skills that influence one's ability to succeed in coping with environmental demands and pressures" (Bar-On 1997:14).

Bar-On (2000) refers to emotional intelligence as a construct and suggests that there is significant overlap between many concepts involved in emotional intelligence. He thus refers to it more generally as emotional and social intelligence. Bar-On's (1997) model is multi-factorial in the sense that it relates to potential for performance and success as opposed to performance per se and is considered to be process oriented, not outcome oriented. The model outlined in table 1 below was expressly operationalised according to 15 conceptual components (emotional skills) pertaining to five specific dimensions of emotional and social intelligence.

Figure 1: Bar-On's model of emotional intelligence (adapted from Stein \& Book 2006)

\begin{tabular}{|c|c|}
\hline INTRA-PERSONAL & INTER-PERSONAL \\
\hline $\begin{array}{ll}\text { - } & \text { Self-regard } \\
\text { - } & \text { Emotional self-awareness } \\
\text { - } & \text { Assertiveness } \\
\text { - } & \text { Independence } \\
\text { - } & \text { Self-actualisation }\end{array}$ & $\begin{array}{ll} & \text { Empathy } \\
\text { - } & \text { Social responsibility } \\
\text { - } & \text { Interpersonal relationships }\end{array}$ \\
\hline ADAPTABILITY & STRESS MANAGEMENT \\
\hline $\begin{array}{ll}\text { - } & \text { Reality testing } \\
\text { - } & \text { Flexibility } \\
\text { - } & \text { Problem solving }\end{array}$ & $\begin{array}{l}\text { - Stress tolerance } \\
\text { - Impulse control }\end{array}$ \\
\hline \multicolumn{2}{|c|}{ GENERAL MOOD: optimism and happiness } \\
\hline EFFEC & FORMANCE \\
\hline
\end{tabular}

It is this framework's comprehensive nature that allows for inclusion and expansion of other existing models of emotional intelligence known to Bar-On. The five general areas or realms with the 15 subsections or scales will be discussed. 
(1) Intrapersonal composite scale (RAeq)

This scale assesses the inner self. It concerns the ability of being aware of and understanding emotions, feelings and ideas in one's inner self and subsequently managing them. High scoring on this composite scale suggests individuals who are able to express their feelings, are independent, strong and confidently able to convey their ideas and beliefs (Stein \& Book 2000). The subscales of this composite scale include the following:

- Self-regard $(S R)$ is defined as the ability to accurately, perceive, understand and accept oneself. Self-regard is the ability to respect and accept oneself as is, accepting both positive and negative elements as well as strengths and weaknesses. A person with good self-regard feels fulfilled, satisfied and selfassured. At the opposite end of the continuum are feelings of personal inadequacy and inferiority (Bar-On 1997).

- Emotional self-awareness (ES) is defined as the ability to be aware of, recognise and be in touch with one's emotions. It is not only the ability to be aware of our emotions, but also to differentiate between them, to know what we are feeling and why, and to know what caused those feelings (Bar-On 1997). Bar-On (2000) suggests that emotional self-awareness is the minimal factor necessary for any model attempting to define emotional intelligence.

- Assertiveness $(A S)$ is defined as the ability to constructively express and defend our feelings, thoughts and beliefs in a non-destructive manner. Assertive people are not overly controlled or shy, and they are able to outwardly express their feelings (often directly) without being aggressive or abusive (Bar-On 1997).

- Independence $(I N)$ is defined as the ability to be autonomous and free of emotional dependency on others. This is the ability to be self-directed in our thinking, actions and making of important decisions. Independent individuals may, however, seek and consider other people's opinions before making 
decisions, but consulting with others is not a sign of dependency in this regard. The ability to be independent rests on one's degree of self-confidence, inner strength as well as a desire to meet expectations and obligations without becoming a slave to them (Bar-On 1997).

- Self-actualisation $(S A)$ is defined as the ability to set personal goals and the drive to achieve them in order to actualise one's potential. Fundamentally, selfactualisation pertains to the ability to realise one's potential capacities. Low levels of self-actualisation are associated with depression (Bar-On 1997).

(2) Interpersonal composite scale (EReq)

This scale connects to interpersonal skills and social capacity and functioning and refers to the ability to interact and get along with others. High scores denote responsible and dependable individuals who are considered to have good social skills (Stein \& Book 2000). The subscales of this composite scale include the following:

- Empathy $(E M)$ is defined as the ability to be aware of, understand and to appreciate how others feel. It is being sensitive to what, how and why people feel the way they do. Empathetic people care about other people and show interest in and concern for them (Bar-On 1997).

- Social responsibility $(R E)$ is defined as the ability to positively identify with one's social group and cooperate with others. It is the ability to demonstrate oneself as a co-operative, contributing and constructive member of a social group. Individuals who are seriously deficient in this ability may entertain anti social attitudes, act abusively towards others and take advantage of people (Bar-On 1997).

- Interpersonal relationships $(I R)$ is defined as the ability to establish and maintain mutually satisfying relationships and relate well with others. Being adept in 
interpersonal relationship skills is characterised by giving and receiving warmth and affection and conveying intimacy (Bar-On 1997).

(3) Stress management (SMeq)

This composite scale concerns one's ability to tolerate, manage and cope with stressful situations. Individuals receiving high scores in this area are generally calm, rarely impulsive and work effectively under pressure (Stein \& Book 2000). The subscales of this scale include the following:

- Stress tolerance $(S T)$ is defined as the ability to effectively and constructively manage emotions. In essence, stress tolerance is the ability to withstand and deal with adverse events and stressful situations without becoming overwhelmed by actively and positively coping with stress. People with a well-developed capacity for stress tolerance tend to face crises and problems instead of surrendering to feelings of helplessness and hopelessness. Anxiety often results when this component of emotional-social intelligence is not functioning adequately (Bar-On 1997).

- Impulse control (IC) is defined as the ability to effectively and constructively control emotions. More precisely, impulse control is the ability to resist or delay an impulse, drive or temptation to act. Problems in impulse control are manifested by low frustration tolerance, impulsiveness, anger control problems, abusiveness, loss of self-control and explosive and unpredictable behaviour (BarOn 1997).

(4) Adaptability composite scale (ADeq)

Here the scale reveals one's ability to cope with and be open to change in dynamic shifting environmental demands and thereby solve a range of problems as they arise. High scores identify individuals who are mostly flexible, pragmatic and able to 
find adequate solutions in problematic situations (Stein \& Book 2000). The subscales of this composite scale include the following:

- Reality testing $(R T)$ which governs the ability to objectively validate our feelings and thinking with external reality. Reality testing, essentially involves "tuning in" to the immediate situation, attempting to keep things in correct perspective and experiencing things as they really are without excessive fantasising or daydreaming about them (Bar-On 1997).

- Flexibility $(F L)$ represents the ability to adapt and adjust one's feelings, thinking and behaviour to changing situations and conditions. Flexible people are agile, synergistic and capable of reacting to change without rigidity. These people are generally open to and tolerant of different ideas, orientations ways and practices (Bar-On 1997).

- Problem solving (PS) governs the ability to effectively solve problems of a personal and interpersonal nature. Problem solving entails the ability to identify and define problems and generate and implement potentially effective solutions. This skill is also associated with a desire to do one's best and to confront problems, instead of avoiding them (Bar-On 1997).

(5) General mood composite scale (GMeq)

This component pertains to the ability to enjoy life and maintain a positive temperament. High scores reflect an ability to be cheerful, positive and hopeful. Individuals with these high scores can contribute to an uplifting and positive climate in the workplace (Stein \& Book 2000). The subscales of this composite scale include the following:

- Optimism $(O P)$ is defined as the ability to maintain a positive and hopeful attitude towards life even in the face of adversity. It represents a positive approach to daily living and a very important motivating factor in whatever we do. Optimism is 
the opposite of pessimism, which is a common symptom of depression (Bar-On 1997).

- Happiness $(H A)$ is defined as the ability to feel content with oneself, others and life in general. It is the ability to feel satisfied with one's life, enjoy others and have fun. The inability to experience happiness and difficulties in generating positive affect in general are often indicative of dissatisfaction, discontent and depressive tendencies (Bar-On 1997).

Based on Bar-On's emotional-social intelligence model, the Bar-On emotional quotient inventory (EQ-i) was developed (Bar-On 2006). The EQ-i has been constructed with the intention to contain a great many nuances and shadings (Stein \& Book 2006). The results generate information at the following three different levels: firstly, in terms of how one is doing as a whole, in comparison with the population at large; secondly, how one is doing in the five realms; and thirdly, a reflection of how one is measured in the 15 scales. "This specificity yields far more pertinent readings than an IQ test, which often provides only a single, cumulative figure" (Stein \&Book 2006:25). The instrument will be discussed in more detail in chapter 3.

Bar-On hypothesises that those individuals with higher than average EQ's are in general more able to meet environmental demands and pressures. Furthermore, he proposes that a deficiency in emotional intelligence can mean a lack of success and the existence of emotional problems. In general, Bar-On considers emotional intelligence and cognitive intelligence to contribute equally to a person's general intelligence, which then suggests a likelihood of one's potential to succeed in life (Bar-On 2002). A limitation of this model lies in its claims to measure some kind of ability through self-report items (Matthews et al. 2001). Furthermore, the EQ-i has been found to be highly susceptible to faking (Day \& Carroll 2008). 


\subsubsection{The legitimacy of emotional intelligence}

"The swiftness with which the concept of emotional intelligence has caught on perhaps inevitably created a gap between what we know and what we need to know" (Emmerling \& Goleman 2003:2). Naysayers have called emotional intelligence a "buzzword" which realistically holds limited credibility (Steiner 1997), while others have proposed that it is simply a new word for a collection of already established competencies (Woodruffe 2001). The conflicting evidence regarding these claims has resulted in many researchers doubting the legitimacy of the construct and sees ongoing debate raging about the definition and nature, measurement, and application of emotional intelligence (Epstein 1998; Hedlund \& Sternburg 2000; Locke 2005; Mayer et al. 2000; Roberts, Zeidner \& Matthews 2002; Spector 2005).

In his review of research surrounding emotional intelligence, Becker (2003) criticised it from two angles. The first is the lack of valid and reliable measures in the area. The argument is that since the construct cannot yet be measured with reasonable accuracy, it is impossible to know whether it is an empirical reality or wishful thinking (Antonakis 2003, 2004). Conte (2005) supports this with his review and critique of El measures, with concerns ranging from scoring concerns for ability-based El measures to discriminant validity concerns for self-report $\mathrm{El}$ measures. The second criticism is rooted in what appears to be problematic conceptualisation, with Becker (2003) stipulating that emotional intelligence is nothing more than general intelligence aimed at emotional phenomena. As sombrely stated by Zeidner, Matthews and Roberts (2004:393), "despite the important role attributed to a wide array of emotional competencies in the workplace, there is currently only a modicum of research supporting the meaningful role attributed to El (and nested emotional competencies) in determining occupational success. Many of the popular claims, presented in the literature regarding the role of EI in determining work success and well being, are rather misleading in that they seem to present scientific studies supporting their claims, while in fact failing to do so. In short, despite some rather fantastic claims to the contrary, the guiding principle appears presently as 'caveat emptor' [i.e. let the buyer beware]." And finally is a view that although many research 
claims are overstated there is some evidence that EI may contribute at some level to successful leadership (Harms \& Credé 2010).

\subsection{LEADERSHIP}

The call for change is loud and clear from Barack Obama's articulation of the need for fundamental change in his inaugural speech as President of the United States of America on 20 January 2009, to His Holiness the Dalai Lama at the youth event "Stand up and be the change" in Manchester, England, on 16 June 2012. According to Kellerman (2012), it is failed leadership in all spheres that has created our current reality and the subsequent need for change.

It is becoming evident that a different kind of leadership is needed, an era in which leadership can navigate the complexities and challenges of the $21^{\text {st }}$ century. But what is required is leadership that is not based on reliance on individual leaders. The place for the single heroic leader who tackles the problem and seemingly with ease creates solutions is at an end (Avolio et al. 2009; Barrett 2011; Block 2008; Hamel \& Breen 2007; Kellerman 2012; Rost 1993; Wheatley 2006). A space for greater levels of collective leadership with recognition for the follower relationship and shared dialogue is needed. The call for a new approach to leadership started 20 years ago and began to reflect a more relevant post-industrial paradigm (Rost 1993). Furthermore, Carter (2009:5) states that "the new imperatives call for new levels of awareness and for leaders who are able to cultivate a shared consciousness to help people come together in order to create the collective conditions for long term sustainability".

This stark reality is forcing organisations to relook their corporate cultures and values exactly like the organisation this research is based on. There is recognition by leadership that employee engagement; community involvement and environmental stewardship are central to increased productivity and creativity (Barrett 1998). Ethics and values are thus essential drivers of leadership behaviour. The implication of this is a need for a shift in organisational values and a change in the leader's way of 
being. Leaders will need to manifest an awareness of personal impact and accountability in their organisational domain and societal context (Barrett 2011; Block 2008).

\subsubsection{The conceptualisation of leadership}

There is no uniformly accepted definition of leadership in the literature and so people are unable to identify it correctly when they see it manifesting. In their review of leadership literature, Bennis and Nanus (2003) note that academic analysis has generated over 850 definitions of leadership. According to Dr. Henk Struwig, "leadership has become the projection of all our positive fantasies around position, rank and power" (Struwig 2012). This concurs with the view that Block (2008:41) has of leadership having become a romanticised notion which "reinforces individualism, putting us in the stance of waiting for the cream to rise, wishing for a great individual to bring light where there was darkness".

The historian, Burns (1978:425), defines leadership as "the reciprocal process of mobilising by persons with certain motives and values, various economic, political and other resources, in a context of competition and conflict, in order to realise goals independently or mutually held by both leaders and followers". This definition espouses hierarchic, linear thinking, which later gave way to a less patriarchal definition by Bass (1990:19) of leadership as "an interaction between two or more members of a group that often involves a structuring or restructuring of the situation and the perception and expectations of the members". Rost's (1993:102) definition of leadership was intentionally selected to convey particular meanings that are underpinned by certain assumptions and values reflective of a transformed, postindustrial model of leadership. "Leadership is an influence relationship among leaders and followers who intend real changes that reflect their mutual purposes".

According to Cashman (1998:20), these definitions, inter alia, focus on the outer manifestation of leadership instead of getting to the essence of leadership itself. Alternatively, leadership exists everywhere in organisations and "is authentic self- 
expression that creates value". Finally, in the current space of shared leadership or citizenship, Block (2008: 85) is clear that we should stop looking for leadership as though it were scarce or lost, or needs to be trained by experts. "Leadership is about intention, convening, valuing relatedness, and presenting choices. It is not a personality characteristic or a matter of style, and therefore it requires nothing more than what all of us already have."

The evolution of leadership thinking seems to have three discrete periods: from early theories arguing that leaders are born, to a body of research exploring how we can learn to become better leaders by adjusting our behaviours, to the most recent theories that focus on the personal values and self of the leader, as well as his/her relationships with others (Bass \& Bass 2008; Northouse 2012). There are also further theories, which are currently emerging that need consideration.

\subsubsection{The born leader (1920s to 1940s)}

In the 1920s, leadership was viewed as being bound up in the genetic disposition and absolute temperament of individuals. Leaders were born with certain essential identifiable traits, which non-leaders did not possess and these were deemed as stable over time. However, both the impact of followers and situational factors were ignored. This trait approach to leadership was foundational in the formulation of other leadership theories (Bass 1990; Bass \& Bass 2008; Burns 1978).

\subsubsection{The grown leader (1940s to 1980s)}

The idea of trait-based theory was challenged by proposing the alternative that leaders are nurtured and developed throughout their lives in a process of learning through experience. These theories do not try to identify the "correct" person for a leadership position. Instead the theories view the leader's behaviour as providing cues for evoking a subordinate's task behaviour. Theories like transactional leadership, social exchange theory and situational leadership view behaviour as the key aspect of leadership (Bass 1990; Northouse 2012). 


\subsubsection{The conscious leader (1990s to present)}

This phase of leadership theory incorporates an intrinsic focus on the qualities and characteristics of leaders, with an emphasis on their personal values as well as the relationship and interaction between leaders and followers. According to Avolio et al. (2009:428), unlike traditional leadership theories, these new leadership models emphasise "symbolic leader behaviour; visionary, inspirational messages; emotional feelings; ideological and moral values; individualised attention; and intellectual stimulation". This humanistic orientation is founded on the belief that inner development is the first step to outward leadership action. A formative theory in this era has been that of transformational leadership, which goes beyond the concept of transaction or exchange to consider the transformative process involved when leaders and followers connect, raise the morality of all stakeholders and stretch their long-term goals. The results of this engagement are potentially transformative for the individual leader, the group of followers and the entire system (Bass \& Avolio 1994; Bass \& Bass 2008).

The above-mentioned theories, although not the focus of this study, have shaped the emergence of other theoretical departure points that will now be explored as the basis for this research.

\subsubsection{Shared, collective or distributed leadership}

This stream of research, along with that of Rost (1993), calls for leadership to be understood as a process and as a relational space as its essential nature. There is growing evidence for shared or collective leadership in organisations as hierarchical levels are dismantled and team-based structures are explored. Shared leadership is not about engaging various team members to ensure consensus but rather a process of inclusivity (Avolio et al. 2009).

According to Block (2008), this concept of leadership means that in addition to embracing their own humanity, which is the responsibility of every individual, the 
core task of leaders is to create the conditions for civic or institutional engagement. The leader's task is to structure the place and experience of these occasions to move the culture towards shared ownership. Avolio et al. (2009) posit that shared leadership is the property of the whole system and not of individuals, and therefore effectiveness in leadership is the result of the connections and relationships between the parts and not due to any one part of the system like the individual leader. Thus leadership for the purposes of this study is conceptualised as about influencing members of a societal system along with an organisational system to be enrolled in the new strategic vision and direction of the business.

Given that the organisation upon which this research is based viewed leadership as an embedded construct, there was a clear understanding that a shift in its context, and the threat of business survival, both nationally and internationally required a change in leadership which inversely meant that an act of leadership would reconstitute the context to varying degrees (Carter 2009; www.valuescentre.com). The critical constructs underpinning this perspective are explored below and formed the basis of the leadership philosophy and conceptual definition adopted by the organisation, as discussed in chapter 1.

\subsubsection{Leadership as a contextually embedded construct}

According to Avolio (2007), in an attempt to move towards identifying and integrating all of the components that make up leadership, there would be a better probability for researchers to calibrate leadership studies in answering the quintessential questions of nature versus nurture, the views that leadership effectiveness is generic or culturally specific, whether context initiates a style of leadership and if the effectiveness of different leadership styles is impacted by contingencies and demands facing both leaders and followers.

The future forms the context from which leadership derives justification and meaning for why and how to act and gives a pre-emptive focus on what to act on in the present. Leaders need insight into the nature of future possibilities and what would 
be appropriate responses relative to the individuals, groups, organisation, community and society being influenced. Leadership is therefore a complete ecological act and to be effective it must be viewed as intrinsically embedded in this context. This inherently makes the definition of leadership essentially unique to the context in which it manifests and thus redundant in any other context (Veldsman 2002).

The essence of this construct is to elevate the study of leadership so that it no longer only focuses on the leader to the exclusion of other equally important components of the leadership process (Rost 1993).

\subsubsection{Strategic leadership}

"A challenge is generatively complex when its future is fundamentally unfamiliar and undetermined; such challenges cannot successfully be addressed by applying 'best practice' solutions from the past, but only by growing new, 'next practice' solutions" (Kahane 2010:5).

Avolio (2007) underscores the critical importance of how at the strategic leadership level, it is not only that a good decision is made but also subsequently how this decision is translated and implemented effectively across levels of the organisation and always remembering the fact that the context will matter. Crossan et al. (2008) reference this type of strategic leadership, leading within and amongst levels of self, others and organisation, as transcendent leadership. This integrates well with the previous notion of leadership as an embedded construct. It is thus strategic leadership, which can span the cross-level requirements of self, other and organisation effectively. A strategy of an institution or organisation is unique thus requiring the appropriate, contextually embedded leadership. 


\subsubsection{Leadership as a non-hierarchical process}

The central theme to be explored is the idea that leadership is not about designated rank but a relational construct. Kellerman (2012) posits that leadership is a process involving leaders and followers functioning in a context of societal, legal and technological change, and that leadership development too often ignores the importance of followership, particularly the dynamic patterns of rank and power, concentrating instead on the individual leader operating in a narrow, somewhat static context. Grint (2005:133) goes even further by describing the field of leadership research, as being theoretically inadequate in that it excludes the component of followers when examining what leadership comprises. Furthermore, it is followers who teach leadership to leaders in that "it only requires the good follower to do nothing for leadership to fail".

There is strong agreement that the command-and-control corporate model is not one that will be viable and create organisational sustainability into the $21^{\text {st }}$ century. In a world of increasing interdependence and rapid change, it is no longer possible to have all the answers as the executive of the organisation nor is it possible to command employees to make the profound systemic changes needed to transform industrial age institutions for the future world of work (Block 2008; Hamel \& Breen 2007; Rost 1993; Senge 1997). Hence leadership in the future will be distributed among diverse individuals and teams who collectively take responsibility for creating the organisation's future. These citizens, as opposed to employees, are core members of an organisational community in pursuit of a common purpose with both responsibilities and rights. A community is a space, which a person belongs to and that belongs to no one individual (Block 2008; Mintzberg 2009). Nussbaum, a thought leader on the subject of Ubuntu, described the beginnings of a movement from separateness to oneness that we are seeing in the $21^{\text {st }}$ century, is necessarily accompanied by a shift in the focus from a celebration of the individual as a hero and leader to an understanding of the necessity of developing collective awareness of the group as an art form and the capacity and desire for a more relational way of being as worldwide trends (Nussbaum, 2010). 
These are essentially not contemporary ideas. Follett, in her 1924 book Creative experience (as cited in Hamel \& Breen 2007) has some decidedly post-industrial views, as highlighted below.

- Leadership is not defined by the exercise of power, but by the ability to grow the sense of power among those who are led. The most fundamental work of a leader is to develop more leaders.

- Adversarial decision-making is enervating for all concerned and problems would be best solved by integration of diverse perspectives from all relevant stakeholders.

- An organisational system is a collection of local communities and growth both individually and collectively, and is maximised when self-organising is advocated.

The idea of transformational leadership (Bass 1985) implies reciprocity of commitment and interpretation between leaders and followers. Where a leader sees the need to respect and understand followers and attempts to motivate them through rational and emotional appeals. Rost (1993) also explores leadership as a process shared equally between leaders and followers. A relationship based on influence, which is fundamentally multi-directional, in that influence flows in all directions and not only from the top down and it is non-coercive which discounts the role of power, authority and dictatorial actions. Hence the focus is on reciprocal relations with leadership being seen as a distributed and shared process of mutual meaning, sense making and engagement, to respond to and influence unique challenges of a dynamic context (Block 2008; Mintzberg 2009).

\subsubsection{Values-based leadership}

Values and ethics are fundamentally linked to organisational behaviour and leadership (Barrett 1998, 2006). It is becoming increasingly apparent that the full integration of ethical standards and values into business practice is not only preferable, but also essential for long-term organisational survival (Parry \& Proctor- 
Thomson 2002). Organisational survival and sustainability are based on prudent strategic decision-making. Decisions can be formulated on the basis of beliefs or on values. Decisions based on beliefs will reflect the historical experience and context of the leadership, which is steeped in past history, habits and traditions. Beliefs are not capable of handling complex new situations, which the individual has never before experienced. The use of values in making decisions is the conscious creation of a future expectation. Values transcend both contexts and experiences, and therefore are not constrained by the past and are adaptable to new situations (Barrett 2006). Our values are central to who we are - they are the anchors and keep us aligned to our authentic self.

Barrett (2011) asserts that the growing emphasis on values-based leadership in organisational functioning is the result of a global shift in the deep-seated assumptions that shape our society and an increased awareness of the causal link between the rapidly growing worldwide environmental and social issues and the philosophy of business. Organisations function best when committed people work in cooperative relationships based on values like respect. Destroy this and the whole institution of business starts to disintegrate as is now evident in so many companies (Mintzberg 2009). The research of Collins and Porras (2000) validates this notion that values-driven companies are some of the most successful organisations globally. When these organisations unite around a shared set of values, they become more flexible, less hierarchical and less bureaucratic, and they develop an enhanced capacity for collective engagement. The performance of the organisation is significantly enhanced when employees share the same values and vision.

Organisations do not transform, but people do, and so whole scale transformation begins with a shift in the values and behaviour of individual leaders (Barrett 1998). It is therefore the fundamental challenge for leadership to create an organisational culture that initiates, supports and encourages employees to ignite their deepest levels of productivity and creativity by finding personal meaning and fulfilment through their work. When leaders have mastered each level of consciousness and are able to respond appropriately and intuitively to any situation or decision that 
arises without being guided by their beliefs, a real shift would have occurred (Barrett 1998).

\subsubsection{Leadership as a systemic construct}

The constructs discussed above are all closely linked and are highly interdependent and essentially speak to a systems approach to leadership. In this perspective, organisations are viewed as open systems, embedded in a fast-changing global systemic environment where survival requires flexibility, adaptation and renewal (Collier \& Esteban 2000). "The dyadic perspective should be replaced by a systems perspective that describes leadership in terms of several distinct but interrelated influence processes at the dyadic, group, and organisational level" (Yukl 1999:301).

At the heart of this perspective is the shift of organisations being viewed as hierarchical, bureaucratic machines to a post-industrial view of organisations as complex adaptive living systems (Avolio et al. 2009; Rost 1993, Senge 1997; Wheatley 1999). The organisation is a living, complex system, not unlike any system one would find in nature (Carter 2009; Wheatley 1999).

Leadership in these dynamic, post-industrial organisations is viewed as the systemic capability of discovering organisational direction and renewal "by encouraging, harnessing and directing creative and innovative capabilities, while simultaneously holding in tension the process of responsiveness to the environment on the one hand, and the maintenance of internal integrity of purpose on the other" (Collier \& Esteban 2000:208). The systemic view of leadership aligns with the thinking of the nature of leadership being the responsibility of all and a multi-directional, influential process based in innovation and change and not a hierarchical, role-based position (Block 2008; Kellerman 2012). This is also reflected in the view of organisational relationships as community based and a collective accountability and responsibility being held for the common good of the whole (Block 2008; Handy 1997; Rost 1993). Humans are essentially social beings needing a broad social system in which to 
operate and thrive; a context or community that acts as a social glue (Mintzberg 2009).

According to Collier and Esteban (2000), systemic leadership is good leadership in that it creates community, and incites autonomy and creativity for an aligned purpose. It also cultivates emergence and organisational renewal, which create an impetus for an effective and sustainable organisation. Individuals in an organisation will stagnate unless they can realise their potential, and are supported and affirmed by the system within which they engage (Barrett 2011; Wheatley 1999). "A challenge is dynamically complex when cause and effect are interdependent and far apart in space and time; such challenges cannot successfully be addressed piece by piece, but only by seeing the system as a whole" (Kahane 2010:5).

The organisational multi-rater formulation was a culmination of these constructs in a customised and tailored 360-degree leadership assessment tool.

\subsubsection{The organisation multi-rater}

The intentional departure point of the multi-rater was the belief that a coherent leadership approach to leading transformation in the organisation required a holistic framework that integrated the desired shift in behaviour and mindset with the desired business change and was representative of the organisational leadership philosophy discussed above. The desired behaviours and mindsets were identified as "worldviews", then synthesised into 'leadership themes' and then calibrated into behavioural statements. The worldview process draws from a systems thinking philosophy that an organisation is made up of complex networks of interdependencies and relationships, and deeper underlying patterns and structures (Wheatley 1999). The leadership construct for this study as represented in the dependent variable is conceptualised as follows (Carter 2009): 


\subsubsection{Be strategic and visionary (STRT)}

As a leader the requirement is to identify immediate and long-term opportunities, processes and practicess for sustainable business growth through innovative thinking and focusing on competitiors and emerging industry trends. Leadership needs to develop and contribute to strategy through accessing the community of leaders and be aware of the social, political and econominc factors that influence the environment in which the organisation operates. Finally, a clear and compelling vision is needed to inspire and align individual fulfillment and action.

\subsubsection{Demonstrate innovative, authentic values-based leadership (VBL)}

Authentic values-based behaviours need to be demonstrated by consistently acting with integrity, delivering on promises and fostering a high performance, innovative culture where success is celebrated, people really matter and are treated equally. This requires leaders to exhibit high levels of self-awareness together with a willingness and openness to learning and self-development along with a commitment to investing in the growth, development and empowerment of others.

\subsubsection{Design organisational systems and processes (OD)}

Leadership needs to design organisational systems and processes to achieve a collective organisational mindset, while promoting functional synergies and efficiencies across the whole organisation and allowing for cluster uniqueness and regional empowerment to thrive.

\subsubsection{Embrace diversity and transformation (DIV)}

There needs to be a focus on proactively attracting andretaining the collective talents and contributions of previously disadvantaged individuals, in the pursuit of organisational objectives. Awareness and sensitivity to difference is crucial and there is a requirement to strive to shift the power dynamics to address past cultural, social 
and economic imbalances to create an organisation that is representative at all levels.

\subsubsection{Focus on delivery and execution (DEL)}

Leadership needs to demonstrate purposeful and aligned action aimed at delivering pre-agreed results and value-add for all key stakeholders, with a consistent focus on achieving high levels of client satisfaction, retention and growth. Furthermore, there is a need to actively address bureaucracy and hold people accountable for delivery through effective performance management processes.

\subsubsection{Good social citizen (CZN)}

Business decisions need to be made that are grounded in strong ethics and benefit the common good. Leaders need to particpate and encourage others to become active in community-based initiatives.

Thus "leadership effectiveness" (LE) in the multi-rater is a contextually and operationally defined construct that is embedded in the unique demands, dynamics and challenges facing organisations mid-way through their recovery and turnaround journey, as discussed in chapter 1 . The construct was operationalised through the translation of the desired shifts necessary to move the organisation from its current to its ideal future, embodied in the worldview process and translated into the leadership themes. These leadership themes were interpreted and translated into the 59 behaviour statements reflected in the multi-rater. The methodology followed in this questionnaire formulation and development will be described in more detail in chapter 3. 


\subsection{INTEGRATION OF EMOTIONAL INTELLIGENCE AND LEADERSHIP}

In order to come together to work collectively as a community, leaders need to be able to engage in a two-way flow of emotional intelligence, where " $I$ " intertwines with "other" or "we" centeredness. Within this reciprocal flow, leaders in the $21^{\text {st }}$ century increasingly need to learn to cope with and hold paradoxes and polarities (Carter 2009). They will need to combine discipline with empathy and combine rational thought with the wisdom of their intuition. Holding emotionally intelligent attitudes provides space for new insights and possibilities to emerge, individually and collectively (Bar-On 2004; Goleman 2004). The capacity for emotional intelligence embodies self-awareness, compassion and sensitivity in an interpersonal arena (Bar-On 2004). Leaders will need to be able to balance the competing demands and needs of multiple stakeholder groupings from within the organisation, immediate environmental communities to broader societal systems (Carter 2009).

According to studies by Drucker (2008), Gardner and Stough (2002), Goleman (1995, 1998), Palmer, Walls, Burgess and Stough (2001), and Rosete and Ciarrochi (2005) and Van Oosten (2013) there appears to be a relationship between emotional intelligence and leadership effectiveness. One study (Antonakis 2004) included in the meta-analysis, cites the claim that emotional intelligence apparently is twice as important as IQ or technical skills for leadership effectiveness as the main argument against emotional intelligence. This implies that emotional intelligence contributes to effective leadership in organisations, although there are variations around the construct of leadership effectiveness and its measurement with some research being more linked to leadership style. Goleman (1998) views leadership as more like an art than a science and describes high levels of emotional intelligence as the golden thread in those leaders who are more effective. Further research conducted by Goleman et al. (2002) explores the role of emotional intelligence and leadership, highlighting certain neuro-scientific links between people and the success and failure of an organisation. They assert that "primal leadership" which considers issues involving people's emotions, is contagious. If a leader resonates energy and enthusiasm, the organisation is likely to flourish and if the leader spreads negativity 
and dissonance, it is likely to fail. Nurturing emotions in the appropriate direction would increase leadership development and potential as well as overall effectiveness in the organisation (Goleman et al. 2002). Goleman (1998) asserts that the past view of emotional intelligence being a "nice to have" for business leaders has now shifted to a "need to have" for the sake of performance.

The South African research of Coetzee and Schaap (2005), Ramchunder and Martins (2014), Stuart and Paquet (2001) and Vrba (2007) corroborates these supportive findings of the relationship between emotional intelligence and leadership, whereas the research of De Miranda (2011) indicates that a relationship exists between emotional intelligence sub-factors and leadership effectiveness and not emotional intelligence as an overall factor.

Antonakis (2004) however, posits that the state of empirical evidence for the relationship between El and leadership remains weak even after 15 years. Further research reported no statistically significant relationship between emotional intelligence and leadership effectiveness (Barbuto \& Burbach 2006; Brown et al. 2006).

Mills (2009:26) conducted a meta-analysis to ascertain if there was empirical evidence to support the inclusion of emotional intelligence as a component of effective leadership. A comprehensive attempt to identify relevant studies on emotional intelligence's impact on leadership effectiveness conducted between 1990 and 2009 produced 141 studies, with 48 studies meeting the criteria for inclusion. This meta-analysis yielded a combined effect of $r=.380$ which can be interpreted as a moderately strong relationship between emotional intelligence and leadership effectiveness. "Although claims of the paramount or essential value of emotional intelligence as a component of leadership may be overstated, it would appear that emotional intelligence is at least an important element in the exercise of effective leadership". 
The aim of this research was to add to the body of knowledge by further exploring the relationship between emotional intelligence and leadership in a South African context and perhaps shed some light for the implications of leadership development in organisations, which would be of value for industrial psychologists, human resources managers and business leaders alike. The study could potentially contribute to the formulating of content and design of leadership development programmes and initiatives as well as focus areas for leadership within a South African context. It would seem evident that any research, which may shed light on the growth and strengthening of leadership capacity, which in turn could impact on effectiveness, would be meaningful and welcome. The long history of leadership research has, according to Kets de Vries $(1993,2001)$, unsuccessfully provided any clear or consistent insight into the nature of leadership and the requirements of an effective leader. It is thus crucial to understand where there is a positive and significant relationship between the level of emotional intelligence and leadership in leaders and furthermore, whether emotional intelligence serve as a predictor of effective leadership.

\subsection{CHAPTER SUMMARY}

The focus of this chapter was on conceptualising the constructs of emotional intelligence and leadership. Both constructs were investigated in terms of an overview and historical perspective, definitions and schools of thought. The chapter ended with a theoretical integration of the constructs and empirical findings from the literature were presented. Chapter 3 contains the research article for this study and reports on the research process and findings. 
CHAPTER 3: RESEARCH ARTICLE

EMOTIONAL INTELLIGENCE AND LEADERSHIP IN A SOUTH AFRICAN FINANCIAL SERVICES INSTITUTION

\author{
ALISON DU TOIT \\ Department of Industrial and Organisational Psychology \\ Unisa
}

Keywords: emotional intelligence, leadership, financial services institution, senior leaders

\begin{abstract}
The purpose of this study was to determine whether there is a relationship between emotional intelligence and leadership effectiveness among senior leaders in a South African financial services organisation. The sample consisted of 973 participants. A convenience sample was used because these leaders were part of a strategic organisational initiative and were engaged in the completion of both measurement instruments as part of this process. All participants completed the Baron EQ-i, in order to measure emotional intelligence, whereas the leadership effectiveness data were obtained from an organisation-specific multi-rater which accessed self-ratings, peer and subordinate ratings as well as manager ratings in terms of leadership behaviours linked to organisational worldviews of leadership effectiveness. The results showed that there was a statistically significant relationship between emotional intelligence and leadership among the leaders, but the prediction value between these variables was not significant.
\end{abstract}




\section{Introduction}

The $21^{\text {st }}$-century culture of global consumption and consumerism is continuously exerting pressure on our planet's resources. We are increasingly inundated with images of chaos and crisis in our ever-changing world. The irony is that although there is such intense fragmentation and polarisation, we are living in a time where the environment and humanity as a whole are increasingly interdependent and wholly connected (Carter \& Nussbaum 2010; De Bettignies \& Lépineux 2009; Glenn, Gordon \& Florescu 2010). The global financial market crisis of 2008 and subsequent Transatlantic banking crisis demonstrated this reality of our world as an interconnected system. Stock markets and financial institutions were rocked with governments of even the wealthiest nations needing to come up with rescue packages to bail out their financial systems (Welfens, 2009, 2011). The South African banking fraternity was just as affected by these challenges and the period of transition (Chauhan 2012).

These complexities have increased the pressure on organisations and leadership to perform and place a tremendous focus on the need to manage the blurring of boundaries (Gitsham \& Pegg 2012; Leslie \& Canwell 2010). How do organisations and leaders manage the paradoxes, cope with these complexities and stay connected to that which is important for sustained business success? The expectations of leaders today are unrealistic and loaded with projections of individual power, prestige and salvation (Kellerman 2012; Struwig 2012). According to De Miranda (2011), many leadership theories today indicate that leadership is transforming at a rapid pace to keep up with globalisation and flattening organisational hierarchies. Leaders operating in such a turbulent environment are required to possess a specific set of skills. Historically, leadership models emphasised hierarchy, charisma and power over followers (Avolio, Walumbwa \& Weber 2009). In contrast, new models emphasise collaboration, shared power and recognition of multiple leadership styles and roles (Block 2012; Hamel 2007; Kellerman 2012; Mintzberg 2009). New models also increasingly emphasise emotional over technical intelligence (Goleman, Boyatzis \& McKee 2002). 
While there are various studies that provide empirical evidence that emotional intelligence has a positive effect on leadership effectiveness as well as popular leadership gurus who support the role of EQ on leadership effectiveness (Kerr, Garvin, Heaton \& Boyle 2006; Collins 2001; Drucker 2008; Goleman 1995, 1998; Leban \& Zulauf 2004; Ruderman, Hannum, Leslie \& Steed 2001; Van Oosten 2013), studies also reflect that emotional intelligence has no statistical significance in leadership effectiveness (Antonakis 2004; Barbuto \& Burbach 2006; Brown, Bryant \& Reilly 2006). However, the above-mentioned studies were conducted predominantly in an international arena and their relevance and applicability in the South African context require further investigation to truly understand the dynamics at play and whether there is a justifiable place for emotional intelligence in the development of leadership capacity towards increased effectiveness.

A number of studies have also been conducted in a South African context (Astrup \& McArthur 2011; Coetzee \& Schaap 2005, Ramchunder \& Martins 2014; Stuart \& Paquet 2001; Vrba 2007) to explore the relationship between emotional intelligence and leadership. The conclusions drawn were that emotional intelligence relates significantly to leadership behaviour and the outcomes of leadership that are considered either effective or ineffective in a rapidly changing environment. However, given the levels of interest in the subject and the amount of vested interest organisations have in developing a resilient, sustainable and effective leadership capacity, there does not seem to be sufficient practical research in this field and certainly not in South Africa specifically. This specific study uses a customised measure of leadership, which is embedded in the organisational context, and therefore it is not entirely comparable with other studies that have used different measures. Hence the research presented is a unique contribution to the understanding of the relationship between emotional intelligence and leadership.

The South African financial services organisation, on which this study is based, is one of the four largest banking groups in South Africa. A period of bad strategic decision-making, shortage of capital, an incorrect reading of interest rates and too much capital overseas led to the organisation being at risk of being shut down in 
2003 (Financial Mail 2006; Leadership Magazine 2009). There was a clear understanding that a shift in business context, and the threat of survival both nationally and internationally required a change in leadership, which inversely meant an act of leadership would reconstitute the context to varying degrees (Carter 2009; www.valuescentre.com). Linking to the work of Barrett (1998), Goleman (1995, 1998) and Bar-On (1997), EQ was seen to be a key factor to include in the transformation process aimed at leaders. EQ was seen to be at the core of rebuilding and restabilising the social fabric and psychological climate of the organisation. It was felt that a safe psychological climate in which people feel comfortable to question practices, admit mistakes and voice dissonance would be a vital contributor to the effectiveness of leadership in the organisation (Hofmann, Morgeson \& Gerras 2003). The decision to bring emotional intelligence into the area of leadership development was introduced to specifically support the transition from a mindset focusing on numbers and IQ to a mindset including humanism, heart, $E Q$ and essentially a whole-person approach (Carter 2009; Financial Mail 2006; www.valuescentre.com).

Hence the purpose of this study was to ascertain whether emotional intelligence could be used as a positive and significant predictor of leadership effectiveness. This would validate the researcher's hypothesis and the results could be used by the organisation to strengthen the focus on emotional intelligence as a critical aspect of leadership development and further broaden the field of knowledge thereby contributing to the practice of Industrial and Organisational psychology.

\section{Emotional intelligence}

Over the past century, cognitive intelligence has been the departure point of understanding an individual's functioning capability, cognitive capacity as well as being a predictor of potential. However, there was an exploration of characteristics other than intelligence which could satisfactorily explain variations in an individual's success (Bar-On 2010). In the 1980s, Dr Reuven Bar-On, had been asking questions around the differentiators for psychological well-being and success. The first experimental phase of Bar-On's research was conducted between 1983 and 
1986 in South Africa, at Rhodes University, as part of his doctoral studies where he "contributed the phrase 'emotional quotient' (EQ) as a measure of emotional intelligence based on his developing model and measure of this construct" (Stein \& Book 2006:16). One of his preliminary motivations was to discover the key factors and components of emotional and social functioning that could guide individuals to better psychological well-being.

Emotional intelligence as a broad construct addresses the emotional, personal, social and survival dimensions of intelligence. However, there seems to be robust debate and lack of consensus around what exactly the definition of emotional intelligence should comprise (Dulewicz \& Higgs 2000). Bar-On's (1997:14) noncognitive model more generically referred to emotional intelligence as "an array of non-cognitive capabilities, competencies and skills that influence one's ability to succeed in coping with environmental demands and pressures".

Bar-On (2000) refers to emotional intelligence as a construct and suggests that there is significant overlap between many concepts involved in emotional intelligence and he thus refers to it more generally as emotional and social intelligence. Bar-On's (1997) model is multi-factorial, and relates to potential for performance and success as opposed to performance per se and is considered to be process oriented not outcome oriented. The model outlined in table 1 below was expressly operationalised according to 15 conceptual components (emotional skills) pertaining to five specific dimensions of emotional and social intelligence. It is this framework's comprehensive nature that allows for inclusion and expansion of other existing models of emotional intelligence known to Bar-On (1997). 
Figure 1: Bar-On's model of emotional intelligence (adapted from Stein \& Book 2006)

\begin{tabular}{|c|c|}
\hline INTRA-PERSONAL & INTER-PERSONAL \\
\hline $\begin{array}{ll}\text { - } & \text { Self-regard } \\
\text { - } & \text { Emotional self-awareness } \\
\text { - } & \text { Assertiveness } \\
\text { - } & \text { Independence } \\
\text { - } & \text { Self-actualisation }\end{array}$ & $\begin{array}{ll}\text { - } & \text { Empathy } \\
\text { - } & \text { Social responsibility } \\
\text { - } & \text { Interpersonal relationships }\end{array}$ \\
\hline ADAPTABILITY & STRESS MANAGEMENT \\
\hline $\begin{array}{ll}\text { - } & \text { Reality testing } \\
\text { - } & \text { Flexibility } \\
\text { - } & \text { Problem solving }\end{array}$ & $\begin{array}{l}\text { - } \\
\text { - }\end{array}$ \\
\hline \multicolumn{2}{|c|}{ GENERAL MOOD: Optimism and happiness } \\
\hline
\end{tabular}

Bar-On (2002) hypothesises that those individuals with higher than average EQs are in general more able to meet environmental demands and pressures. Furthermore, he proposes that a deficiency in emotional intelligence can mean a lack of success and the existence of emotional problems. In general, he considers emotional and cognitive intelligence to contribute equally to a person's general intelligence, which then suggests a likelihood of one's potential to succeed in life (Bar-On 2002). A limitation of this model lies in its claims to measure some kind of ability through selfreport items (Matthews, Zeidner \& Roberts 2001). Furthermore, the EQ-i has been found to be highly susceptible to faking (Day \& Carroll 2008).

According to the seminal work of Salovey and Mayer (1990), emotions are fundamentally driving forces that arouse, direct and sustain activity. Hence emotional life can be managed with greater or lesser skill and requires a unique set of competencies. Emotional intelligence is an essential aspect in determining one's ability to succeed in life and is understood to directly influence one's state of mind or overall degree of emotional health (Bar-On 1997). Based on these insights, Stuart and Paquet (2001:30) postulate, "emotional health should also have some impact on the presence or absence of leadership ability". 


\section{Leadership}

It is becoming evident that a different kind of leadership is needed in the $21^{\text {st }}$ century, for it is an era of many complexities and challenges. What is required is leadership that is not based on reliance on individual leaders. The place for the single heroic leader who tackles the problem and seemingly with ease creates solutions is an end (Avolio et al. 2009; Barrett 2011; Block 2008; Hamel \& Breen 2007; Kellerman 2012; Rost 1993; Wheatley 2006). A space for greater levels of collective leadership with recognition for the follower relationship and shared dialogue is needed. The call for a new approach to leadership began 20 years ago involving "a paradigm shift which changes our understanding of leadership so that it makes sense in a postindustrial world" (Rost 1993:99).

There is no uniformly accepted definition of leadership in the literature and so people are unable to identify it correctly when they see it manifesting. In their review of leadership literature, Bennis and Nanus (2003) note that academic analysis has generated over 850 definitions of leadership.

The evolution of leadership thinking seems to have three discrete periods: from early theories arguing that leaders are born, to a body of research exploring how we can learn to become better leaders by adjusting our behaviours, to the most recent theories that focus on the personal values and selves of leaders, as well as their relationships with others (Bass \& Bass 2008; Northouse 2012). The traditional approaches to leadership emphasise an individual focus, are leader-centric, dyadic and have a small group view, which is a meso/micro perspective (Carter 2009). Subsequently, the focus has been on behaviours manifesting in the leader-follower relationship and not on the strategic responsibilities of leadership in shaping a strategy that provides an architecture enabling the organisation to grow and flourish in a dynamic environment. In the past, the macro and contextual aspects of leadership have essentially been given little attention (Avolio 2007; Crossan, Vera \& Nanjad 2008). Carter (2009) clearly stated that the organisation in this study could not look at the effectiveness of their leaders as separate from their context, given the bleak reality of financial survival, and needed to understand that leadership 
effectiveness is moderated by the dynamics of context and the environment. Hence the paradigm adopted by the organisation builds on the traditional models of leadership to include a more integrated, holistic and multi-level approach to leadership. These levels acknowledge intrapersonal, interpersonal, organisational and societal implications for leadership.

In this study, leadership was to be understood as a process and as a relational space in its essential nature. There is growing evidence of this shared or collective leadership in organisations as hierarchical levels are dismantled and team-based structures are explored. Shared leadership is generally viewed "as a process versus a person engaging multiple members of the team" (Avolio et al. 2009:431). According to Block (2008), this concept of leadership means that in addition to embracing their own humanity, which is the responsibility of every individual, the core task of leaders is to create the conditions for civic or institutional engagement. The leader's task is to structure the place and experience of these occasions to move the culture towards shared ownership. Avolio et al. (2009) hold the view of shared leadership as being the property of the whole system and not of individuals, and effectiveness in leadership is thus as a result of the connections and relationships between the parts and not because of any one part of the system like the individual leader.

The critical constructs of leadership being a contextually embedded construct, strategic, a non-hierarchical process, values-based and systemic, which underpin this perspective, formed the basis of the leadership paradigm measured in the organisational multi-rater. Thus "leadership effectiveness" (LE) in the multi-rater is a contextually and operationally defined construct that is embedded in the unique demands, dynamics and challenges facing the organisation mid-way through its recovery and turnaround journey.

\section{Integration of the constructs}

According to studies by Drucker (2008), Gardner and Stough (2002), Goleman (1995, 1998), Palmer, Walls, Burgess and Stough (2001) and Rosete and Ciarrochi 
(2005), there appears to be a relationship between emotional intelligence and leadership effectiveness. One study (Antonakis 2004) included in the meta-analysis cites the claims that emotional intelligence is apparently twice as important as IQ and technical skills for leadership effectiveness as the main argument against emotional intelligence. This implies that emotional intelligence contributes to effective leadership in organisations. There are, however variations around the construct of leadership effectiveness and its measurement with some research being more linked to leadership style.

According to Goleman (1998:94) leadership is more like an art than a science and "the most effective leaders are alike in one crucial way: they all have a high degree of what has come to be known as emotional intelligence". Further research conducted by Goleman et al. (2002) explores the role of emotional intelligence and leadership, highlighting certain neuro-scientific links between people and the success and failure of an organisation. They assert that "primal leadership" which considers issues involving people's emotions, is contagious. If a leader resonates energy and enthusiasm, the organisation is likely to flourish and if the leader spreads negativity and dissonance, it is likely to fail. Nurturing emotions in the appropriate direction would increase leadership development and potential as well as overall effectiveness within the organisation (Goleman et al. 2002). According to Goleman (1998), the past view of emotional intelligence being a "nice to have" for business leaders has now shifted to a "need to have" for the sake of performance.

The South African research of Coetzee and Schaap (2005), Ramchunder and Martins 2014, Stuart and Paquet (2001) and Vrba (2007) corroborates these supportive findings of the relationship between emotional intelligence and leadership, whereas the research of De Miranda (2011) indicates that a relationship exists between emotional intelligence sub-factors and leadership effectiveness and not emotional intelligence as an overall factor.

Antonakis (2004), however, points out that the state of empirical evidence for the relationship between $\mathrm{El}$ and leadership remains weak even after 15 years. Further 
research reported no statistical significance between emotional intelligence and leadership effectiveness (Barbuto \& Burbach 2006; Brown et al. 2006).

Mills (2009) conducted a meta-analysis to ascertain if there was empirical evidence to support the inclusion of emotional intelligence as a component of effective leadership. "Although claims of the paramount or essential value of emotional intelligence as a component of leadership may be overstated, it would appear that emotional intelligence is at least an important element in the exercise of effective leadership" (Mills 2009:26).

When taking into consideration the potential contribution of emotional intelligence to the scientific and applied fields of industrial psychology in a South African context, as well as its possible value in leveraging the development of leadership, it becomes evident that research into the relationship of these variables is certainly meaningful to pursue.

The objective of the study was to determine whether there is a relationship between the level of emotional intelligence and leadership in leaders in a South African financial services institution and furthermore, whether emotional intelligence and its components, serve as a predictor of effective leadership.

\section{Method}

\section{Research approach}

The empirical study followed a non-experimental research design to determine the relationship between emotional intelligence and leadership. A quantitative approach to the study was proposed with a cross-sectional survey design to gather data on emotional intelligence and leadership effectiveness in a South African financial services institution (Babbie \& Mouton 2009). The responses were collected by means of convenience sampling. The use of an electronic survey methodology ensured that the leaders' responses were captured at a single point and time (Babbie \& Mouton 2009). 


\section{Participants}

The unit of analysis for the purposes of this research was individuals, namely male and female senior leaders. These leaders are employed as functional members of the organisation. This research was conducted in a South African financial services institution, employing a total of 27000 employees. The sample unit in this study consisted of individual leaders in executive and senior-level management positions $(n=1800)$ geographically dispersed across all business units and disciplines who were strategically identified on basis of the scope, capacity and budget linked to a specific organisational leadership development programme. This population ( $n=1800$ ) represented a non-random sample of convenience due to their pre-existing involvement in the organisational leadership development programme which required that they complete the measurements used in this study and given that they were holding leadership positions that were part of the first phase roll out on the programme. The sample was not created for the purpose of this study but was accessible and approved for the researcher to use. The final sample was 973 respondents $(n=973)$. Table 1 indicates the biographical properties of the respondents who were included in the study and serves to describe the sampled population.

Table 1: Sample characteristics $(n=973)$

\begin{tabular}{llll}
\hline Variable & Category & Frequency & Percentage \\
\hline Gender & Male & 629 & 64.6 \\
& Female & 344 & 35.4 \\
Age (years) & & & \\
& $25-34$ & 220 & 22.6 \\
& $35-44$ & 453 & 46.6 \\
& $45-64$ & 293 & 30.1 \\
& Missing & 7 & 0.7 \\
\hline
\end{tabular}

The age of the respondents was distributed as follows: $22 \%$ of the respondents fell into the 25- to 34-year-old age category; the 35- to 44-year-old category comprised the largest portion of the sample at $46 \% ; 30 \%$ fell into in the 45 - to 64 -year-old age 
category; and $7 \%$ of the respondents could not be categorised as their data was missing on the system. The frequency distribution of the data is in line with expectations for people at that strategic level in the organisation. There was approximately double the number of males than females, with males comprising $64 \%$ of the respondents and females $35 \%$. Since the organisationally embedded perspective of leadership is viewed as a values-based, non-hierarchical construct, further biographical variables specifically linked to race, organisational position and tenure were not deemed relevant, not measured and therefore are not reflected here.

\section{Measuring instruments}

The measuring instruments utilised in the empirical study were the Bar-On emotional-social intelligence model (EQ-i) (Bar-On 1997) and the 360-degree leadership assessment instrument designed specifically for the organisation by a panel of experts namely, the organisation multi-rater. The necessary biographical data were extracted from these instruments thus no separate biographical questionnaire was administered.

The Bar-On emotional quotient inventory $(E Q-i)$ is a self-report measure designed by Bar-On (1997) to measure a number of constructs relating to emotional intelligence. The EQ-i consists of 133 items and takes approximately 30 minutes to complete. Items are answered using a five-point Likert scale where 1 indicates "very seldom or not true of me" and 5 "very often true of me". It gives an overall EQ score as well as scores for five composite scales: intrapersonal, interpersonal, adaptability, stress management and general mood and then is further broken down into 15 subscales (Bar-On 2006). It does not measure personality traits or cognitive capacity, but instead the mental ability to be successful in managing environmental demands and stresses. The internal consistencies for the 15 subscales range between 0.69 and 0.86 with an overall average internal consistency of 0.76 (Bar-On 1997). South African norm data collated by Jopie van Rooyen and Partners, from a normative sample consisting of 9892 respondents indicates that South African EQ-i norms appear stable and possess little measurement error. Their findings reflect that the 
norms also approximate a normal distribution. What did emerge was that South African norms were significantly higher than North American norms across the majority of EQ-i scales. Then finally the EQ-i scales demonstrated acceptable to very high levels of internal consistency in the South African sample. The scales were also moderately inter-correlated (Taylor 2006).

The organisations own multi-rater was used to assess leadership. This is a customised 360-degree assessment that focuses on the following six leadership themes: strategy, values-based leadership, organisation design, diversity/transformation, delivery and execution and good social citizen; and five other values as the measured dimensions. It includes 59 items. The questionnaire was developed by a panel of experts to ensure a framework that integrated the desired shift in leadership behaviour and mindset with the desired business change for the organisation. The desired behaviours and mindsets were identified as "worldviews", then synthesised into "leadership themes", and then calibrated into behavioural statements. A research psychologist from Jopie van Rooyen and Partners provided assistance to ensure a statistically sound and robust process in instrument development. After testing reliability following an iterative process, the data stabilised at a Cronbach alpha reliability of 0.97 . A factor analysis was conducted and initially there were factor loadings that did not corroborate the leadership theme as classified in the statement list used for the Q-sort. Some statements were then reworded in order to ensure that the statements gravitated closer to the intended factor solution. The validity testing was done on the remaining statements after eliminating "unstable" statements rejected by the reliability testing and the validity was found to be $60.2 \%$. After the Q-sort phase, reliability and validity testing, the panel reviewed the statements once more in order to ensure alignment with the worldviews and values. The final measurement instrument was compiled which contained reduced behaviour statements that evaluated the leaders' demonstration of group values as well as the leadership themes that exemplify the desired state of the transformed organisation. Once key stakeholders had signed off the questionnaire, it was web-enabled and hosted on the web. Assessment required two levels: (1) the respondent had to assess himself/herself on the instrument; and 
(2) the respondent had to be assessed by nine raters: manager peers/colleagues and direct reports/subordinates.

Thus "leadership effectiveness" in the multi-rater is a contextually and operationally defined construct that is embedded in the unique demands, dynamics and challenges facing this specific organisation.

\section{Research procedure}

This study did not involve primary data collection. Because an organisational leadership development programme initiated the data collation, existing data was used for comparative analysis and study. Written permission and consent was granted by the CEO of the organisation to make use of the data and include them in this study by explaining the potential value the research could have for the organisation.

During the initial data collection process, a communication was sent to all participants by their business unit head outlining the overall programme, its purpose and rationale. An e-mail was then sent to all participants as an invitation to participate. This e-mail explained the process of the self-assessment aspect of the two questionnaires as well as the nomination of raters for the multi-rater. Each participant was asked to register using a link of the service provider used for the electronic administration of the questionnaires to ensure complete confidentiality. The participants were each given a unique registration code to ensure the tracking of all their specific feedback. The participants were then asked to nominate raters for the multi-rater assessment of which one needed to be their manager and the other eight divided equally among peers and direct reports. Assessment required two levels: (1) the respondent had to assess himself/herself on both measuring instruments; and (2) the respondent had to be assessed by nine raters (manager, peers/colleagues and direct reports/subordinates) on the multi-rater instrument. Finally, a project support team, external to the organisation, was used to track and monitor participant and rater completion. This was all done electronically. 


\section{Statistical analysis}

The statistical analysis was carried out in STATISTICA (version 10) (StatSoft, Inc. 2011). Means, standard deviations, skewness and kurtosis were used to describe the univariate characteristics of the data. Cronbach's alpha was used to determine the construct validity and reliability of the measuring instruments. Correlations were calculated to investigate the presence of relationships (Babbie \& Mouton 2009). Forward and backward selection multiple regression analyses were used to explore the relationships between the five emotional intelligence scales and each of the seven leadership dimensions (Hair, Tatham, Black, Anderson \& Black 1998).

\section{Results}

The descriptive data for both the independent variable (emotional intelligence) and dependent variable (leadership) were calculated along with their various subscales. Table 2 presents the means, standard deviations, minimum and maximum scores, normalized skewness and kurtosis, test for non-normality and finally the Cronbach's alpha reliability coefficients for the emotional intelligence scales and subscales as self-reported on the Bar-On EQi by the sample. The results indicate that all the measures have acceptable to good levels of internal consistency, ranging from 0.72 to 0.96 , which is higher than the accepted suggested cut-off point of 0.70 (Tavakol \& Dennik 2011). 
Table 2: Descriptive analysis for the EQi $(n=973)$

\begin{tabular}{|c|c|c|c|c|c|c|c|c|}
\hline Item & Mean & SD & Min & Max & $\begin{array}{c}\text { z } \\
\text { (skewness) }\end{array}$ & $\begin{array}{c}\mathrm{z} \\
\text { (kurtosis) }\end{array}$ & $\begin{array}{c}\text { Significant } \\
\text { non- } \\
\text { normality? } \\
\text { (Kolmogorov } \\
\text {-Smirnov } \\
\text { test at } 1 \% \\
\text { significance } \\
\text { level) }\end{array}$ & $\begin{array}{c}\text { Cronbach's } \\
\text { alpha }\end{array}$ \\
\hline Total EQ & 103.19 & 13.97 & 55 & 138 & -3.55 & -1.36 & & 0.96 \\
\hline Intrapersonal EQ & 103.15 & 14.11 & 41 & 131 & -6.92 & 1.04 & Yes & 0.93 \\
\hline Self-regard & 102.28 & 12.49 & 48 & 126 & -10.12 & 2.34 & Yes & 0.88 \\
\hline Emotional self-awareness & 100.88 & 14.70 & 42 & 131 & -4.37 & -0.39 & & 0.84 \\
\hline Assertiveness & 102.52 & 14.47 & 47 & 131 & -5.56 & 0.46 & Yes & 0.82 \\
\hline Independence & 104.94 & 12.95 & 50 & 128 & -6.73 & 1.05 & Yes & 0.74 \\
\hline Self-actualisation & 101.14 & 13.87 & 54 & 129 & -8.89 & 0.35 & Yes & 0.83 \\
\hline Interpersonal EQ & 99.82 & 14.01 & 48 & 134 & -3.65 & -0.89 & & 0.88 \\
\hline Empathy & 100.52 & 14.19 & 42 & 126 & -4.94 & 0.42 & Yes & 0.75 \\
\hline Social responsibility & 102.24 & 12.96 & 54 & 135 & -6.07 & 0.64 & Yes & 0.72 \\
\hline Interpersonal relationships & 97.79 & 14.32 & 51 & 130 & -4.35 & -0.48 & & 0.83 \\
\hline Stress management EQ & 102.52 & 13.05 & 62 & 137 & -2.32 & -0.54 & & 0.84 \\
\hline Stress tolerance & 103.13 & 13.46 & 51 & 135 & -3.18 & -1.55 & & 0.82 \\
\hline Impulse control & 101.15 & 13.44 & 49 & 133 & -7.09 & 3.76 & & 0.80 \\
\hline Adaptability EQ & 103.30 & 13.47 & 61 & 136 & -0.99 & -2.35 & & 0.87 \\
\hline Reality testing & 104.31 & 13.12 & 57 & 135 & -3.56 & -2.20 & Yes & 0.76 \\
\hline Flexibility & 101.31 & 14.55 & 49 & 134 & -3.40 & -1.92 & & 0.80 \\
\hline Problem solving & 101.96 & 13.72 & 53 & 129 & -3.70 & -1.80 & & 0.79 \\
\hline General mood EQ & 101.71 & 13.00 & 41 & 130 & -7.88 & 2.30 & Yes & 0.86 \\
\hline Optimism & 102.37 & 13.14 & 44 & 130 & -6.66 & 1.51 & Yes & 0.77 \\
\hline Happiness & 101.09 & 13.31 & 51 & 124 & -9.93 & 2.88 & Yes & 0.81 \\
\hline
\end{tabular}

The reflected total EQ mean score of 103.19 and standard deviation of 13.97 are comparable to the normative mean of the EQi, which is 100 and standard deviation of 15 (Bar-On 2004). It is also highly comparable to the South African norm data which reflect a total EQ score of 104.63 and a standard deviation of 12.55. Finally, this is also comparable with all of the scales and subscales in table 2. For the remaining data analysis, the focus is on the five $E Q$ scales with the six leadership scales and the overall leadership scale. The EQ subscales were not included because they did not form part of this research and its aims. The test for nonnormality shows several variables exhibited significant non-normality.

Table 3 reports the means, standard deviations, minimum and maximum scores, normalized skewness and kurtosis and then Cronbach's alpha reliability coefficients 
for the organisational multi-rater and leadership themes as rated by the sample participants themselves and their nominated raters. Some of the data was missing in the leadership variables, particularly in the diversity scale. However, the amount of missing data is very small ( $2 \%$ in the worst case). In these instances, cases with missing data were deleted for affected analyses. Again the results demonstrate appropriate levels of internal consistency, with Cronbach alphas ranging from 0.75 to 0.94.

Table 3: Descriptive analysis for the leadership multi-rater $(n=973)$

\begin{tabular}{|c|c|c|c|c|c|c|c|c|c|}
\hline Item & $\mathrm{N}$ & Mean & SD & Min & Max & $\begin{array}{c}\text { z } \\
\text { (skewness) }\end{array}$ & $\begin{array}{c}\text { Z } \\
\text { (kurtosis) }\end{array}$ & $\begin{array}{c}\text { Significant } \\
\text { non- } \\
\text { normality? } \\
\text { (Kolmogorov } \\
\text {-Smirnov } \\
\text { test at } 1 \% \\
\text { significance } \\
\text { level) }\end{array}$ & $\begin{array}{c}\text { Cronbach's } \\
\text { Alpha }\end{array}$ \\
\hline $\begin{array}{l}\text { Leadership effectiveness } \\
\text { overall }\end{array}$ & 973 & 4.0 & 0.3 & 2.2 & 5.0 & -10.57 & 11.76 & Yes & $\mathrm{n} / \mathrm{a}$ \\
\hline Strategy & 972 & 24.2 & 1.8 & 16.5 & 30.0 & -3.38 & 2.80 & & 0.75 \\
\hline Values-based leadership & 969 & 91.0 & 5.8 & 68.7 & 108.0 & -4.93 & 3.29 & & 0.94 \\
\hline Organisational design & 964 & 28.8 & 1.9 & 21.4 & 35.0 & -5.69 & 3.48 & & 0.87 \\
\hline Diversity/transformation & 952 & 28.9 & 2.1 & 20.9 & 35.0 & -5.22 & 3.04 & & 0.84 \\
\hline Delivery and execution & 965 & 54.5 & 3.6 & 39.1 & 65.0 & -6.99 & 6.25 & & 0.89 \\
\hline Good social citizen & 962 & 15.4 & 1.5 & 8.0 & 20.0 & -5.07 & 4.32 & & 0.81 \\
\hline
\end{tabular}

Skewness and kurtosis are considered to assess if data is normally distributed. A skewness value of zero implies a normal distribution (McNeese 2008). In tables 2 and 3 , all except two of the variables were significantly negatively skewed. Such distributions are typical of rating scales where many respondents rate/are rated near the top of the scale, with few rating/being rated negatively. This skewness results in several of the variables exhibiting significant non-normality. This has implications for the correlation analysis. Given the non-normality of several of the variables in this study, the decision to use non-parametric stats for the correlations is justified given that the use of Pearson's correlation was not appropriate since this assumes normality of the data. Instead, the non-parametric alternative, Spearman's rank correlation was used (Babbie \& Mouton 2009). 
The relationships between the scales of emotional intelligence and leadership and their dimensions were investigated. The matrix of inter-correlations between the dimensions measured by the Bar-On EQi and the leadership multi-rater are reported in table 4. Almost all the correlations were significant, including many with very low correlation coefficients, and this is a result of the large sample size (Cohen 1977).Thus effect size needs to be considered to decipher which correlations are really important. Cohen's (1977) effect size for correlation coefficients is applied here as follows: $(r)<0.1$, near zero effect size; $(r)$ between 0.1 and 0.3 , small effect size; $(r)$ between 0.3 and 0.5 , moderate effect size; and $(r)>0.5$, large effect size. There were no correlations with large effect size or even moderate effect size between any of the $E Q$ and leadership variables. All correlations indicated in table 4 between the EQ and leadership variables represent a small effect size.

Each of the emotional intelligence scales, namely intrapersonal (RAeq), interpersonal (EReq), stress management (SMeq), adaptability (ADeq) and general mood (GMeq), correlated strongly with the total EQ scale and significantly with each other, ranging from a minimum of $r=0.34(p=<0.01)$ to a maximum of $r=0.87$ $(p=<0.01$ ), which confirms previous correlation research findings (Bar-On 2004; Dawda \& Hart 1999; Newsome Day \& Catano 2000) and suggests a moderate to high practical significance (Cohen 1977). The strongest correlations were between RAeq/ADeq $(\mathrm{r}=0.74 ; p=<0.01)$ and RAeq/GMeq $(\mathrm{r}=0.76 ; p=<0.01)$.

The dimensions of leadership, being strategy (STRT), values-based leadership (VBL), organisation design (OD), diversity/transformation (DIV), delivery and execution (DEL) and good social citizen (CZN), correlated strongly with total leadership scores (TOTALL) and also yielded significant correlations with one another. The strongest correlations were between VBL/OD $(r=0.84 ; p=<0.01)$ and VBL/DIV $(r=0.82 ; p=<0.01)$. 
Table 4: Intercorrelations for the emotional intelligence dimensions of the EQi and the leadership dimensions of the multi-rater $(n=973)$

\begin{tabular}{|c|c|c|c|c|c|c|c|c|c|c|c|c|c|}
\hline & $\begin{array}{l}\text { TOTAL } \\
\text { EQ }\end{array}$ & RAeq & EReq & SMeq & ADeq & GMeq & $\begin{array}{l}\text { TOTAL } \\
\text { L }\end{array}$ & STRT & VBL & OD & DIV & DEL & CZN \\
\hline $\begin{array}{l}\text { TOTAL } \\
\text { EQ }\end{array}$ & 1,00 & & & & & & & & & & & & \\
\hline RAeq & $0.92^{* *}$ & 1.00 & & & & & & & & & & & \\
\hline EReq & $0.72^{* *}$ & $0.59^{* *}$ & 1.00 & & & & & & & & & & \\
\hline SMeq & $0.71^{* *}$ & $0.54^{* *}$ & $0.34^{* *}$ & 1.00 & & & & & & & & & \\
\hline ADeq & $0.87^{* *}$ & $0.74^{\star *}$ & $0.50^{\star *}$ & $0.66^{* *}$ & 1.00 & & & & & & & & \\
\hline GMeq & $0.81^{* *}$ & $0.76^{\star *}$ & $0.62^{\star *}$ & $0.49^{* *}$ & $0.61^{* *}$ & 1.00 & & & & & & & \\
\hline $\begin{array}{l}\text { TOTAL } \\
\text { L }\end{array}$ & $0.15^{\star *}$ & $0.18^{\star *}$ & 0.06 & $0.08^{*}$ & $0.09^{\star \star}$ & $0.16^{\star \star}$ & 1.00 & & & & & & \\
\hline STRT & $0.24^{\star *}$ & $0.26^{\star *}$ & $0.19^{\star *}$ & $0.14^{\star *}$ & $0.17^{\star \star}$ & $0.24^{\star *}$ & $0.62^{* *}$ & 1.00 & & & & & \\
\hline VBL & $0.16^{\star *}$ & $0.13^{* *}$ & $0.20^{\star *}$ & $0.13^{\star *}$ & $0.10^{\star *}$ & $0.13^{\star *}$ & $0.66^{* *}$ & $0.74^{* *}$ & 1.00 & & & & \\
\hline$O D$ & $0.17^{\star *}$ & $0.16^{\star *}$ & $0.19^{\star *}$ & $0.10^{\star \star}$ & $0.12^{\star \star}$ & $0.16^{\star \star}$ & $0.62^{* *}$ & $0.78^{* *}$ & $0.84^{* *}$ & 1.00 & & & \\
\hline DIV & $0.15^{\star *}$ & $0.11^{* *}$ & $0.21^{\star *}$ & $0.15^{\star \star}$ & $0.09^{* *}$ & $0.08^{*}$ & $0.47^{* *}$ & $0.63^{* *}$ & $0.82^{* *}$ & $0.73^{\star *}$ & 1.00 & & \\
\hline DEL & $0.16^{\star *}$ & $0.20^{\star *}$ & $0.09^{* *}$ & 0.06 & $0.12^{\star \star}$ & $0.13^{\star *}$ & $0.71^{* *}$ & $0.73^{* *}$ & $0.75^{\star *}$ & $0.75^{\star *}$ & $0.53^{* \star}$ & 1.00 & \\
\hline CZN & $0.17^{\star *}$ & $0.13^{\star *}$ & $0.23^{* *}$ & $0.12^{* *}$ & $0.08^{\star *}$ & $0.15^{\star \star}$ & $0.37^{\star *}$ & $0.60^{* *}$ & $0.60^{* *}$ & $0.62^{* *}$ & $0.61^{* *}$ & $0.45^{\star *}$ & 1.00 \\
\hline
\end{tabular}

The TOTAL EQ and TOTALL relationship emerged as slightly correlated $(r=0.15$; $p=<0.01$ ), which indicates that senior leaders who have higher levels of $E Q$ also manifest signs of leadership effectiveness. Although the results reflect a relationship between the variables, they do not indicate a significant positive relationship between EQ and leadership. Cohen's (1977) effect size value suggests a small practical significance here.

No statistically significant relationships emerged between EReq and TOTALL $(r=0.06)$, or between SMeq and DEL $(r=0.06)$.

The highest correlations between the leadership dimensions and EQ scales can be highlighted. TOTAL EQ was significantly correlated with STRT $(r=0.24 ; p=<0.01)$. 
RAeq correlates significantly with STRT $(r=0.26 ; p=<0.01)$. EReq correlates significantly with the leadership dimensions VBL $(r=0.20)$, DIV $(r=0.21 ; p=<0.01)$ and CZN $(r=0.23 ; p=<0.01)$. Lastly, GMeq correlates significantly with STRT $(r=0.24$; $p=<0.01)$.

In table 5 the results of forward selection multiple regression analyses are provided with the scales of emotional intelligence as the independent variables and each of the seven dimensions of leadership, used in turn as the dependent variable. The purpose of the regressions was to determine which $E Q$ variables had a significant influence on each of the leadership variables, and to also determine the magnitude of the relationship between the independent and dependent variables.

In each case, forward and backward stepwise regression analysis was performed to select the best subset of independent variables for each dependent variable (Hair et al. 1998). Prior to this, the diagnostics for the full model (the model including all the independent variables) were inspected for the effects of multicollinearity, of which there was none (Belsley, Kuh \&Welsch 1980). Individual models were diagnosed for outliers, influential points and non-normality of residuals (Hair et al. 1998). Apart from the removal of three to five outliers (depending on the particular model), no other problems with model fit were experienced. It was found that the results from the forward stepwise regression consistently produced models with the same or higher adjusted $R^{2}$ values compared to those from the backward stepwise regression. Hence only the results from the forward stepwise regression were considered. 
Table 5: Results of forward selection multiple regression analysis with the leadership dimensions overall leadership, strategy, values-based leadership, organisational design, diversity, delivery and citizenship as dependent variables and emotional intelligence subscales as the independent variables

\begin{tabular}{|c|c|c|c|c|c|}
\hline \multirow[t]{2}{*}{ Model } & \multicolumn{2}{|c|}{$\begin{array}{c}\text { Non-standardised } \\
\text { coefficients }\end{array}$} & \multirow{2}{*}{$\begin{array}{c}\text { Standardised } \\
\text { coefficients } \\
\text { Beta }\end{array}$} & \multirow[t]{2}{*}{$t$} & \multirow[t]{2}{*}{$p$} \\
\hline & $B$ & Std. error & & & \\
\hline \multicolumn{6}{|l|}{ TOTALL } \\
\hline Intercept & 3.643 & 0.085 & & 43.06 & $<0.0001$ \\
\hline RAeq & 0.004 & 0.001 & 0.189 & 3.22 & 0.0013 \\
\hline EReq & -0.002 & 0.001 & -0.116 & -2.84 & 0.0047 \\
\hline GMeq & $\begin{array}{r}0.004 \\
0-0 ? 2 ?\end{array}$ & $\begin{array}{c}0.001 \\
p^{2}=005\end{array}$ & 0.152 & 2.90 & 0.0038 \\
\hline \multicolumn{6}{|l|}{ STRT } \\
\hline Intercept & 20.434 & 0.483 & & 42.30 & $<0.0001$ \\
\hline RAeq & 0.025 & 0.007 & 0.198 & 3.43 & 0.000627 \\
\hline \multirow[t]{2}{*}{ GMeq } & 0.014 & 0.007 & 0.101 & 1.97 & 0.04933 \\
\hline & $R=0.28$ & $R^{2}=0.78$ & Adjusted $R^{2}=0.074$ & & \\
\hline \multicolumn{6}{|l|}{ VBL } \\
\hline Intercept & 80.920 & 1.668 & & 48.51 & $<0.0001$ \\
\hline EReq & 0.083 & 0.015 & 0.204 & 5.60 & $<0.0001$ \\
\hline SMeq & 0.044 & 0.018 & 0.102 & 2.43 & 0.0154 \\
\hline & $R=0.22$ & $R^{2}=0.05$ & Adjusted $R^{2}=0.046$ & & \\
\hline \multicolumn{6}{|l|}{ OD } \\
\hline Intercept & 25.713 & 0.494 & & 52.05 & $<0.0001$ \\
\hline EReq & 0.017 & 0.005 & 0.128 & 3.21 & 0.0014 \\
\hline GMeq & 0.014 & 0.006 & 0.097 & 2.44 & 0.0149 \\
\hline & $R=0.20$ & $R^{2}=0.04$ & Adjusted $R^{2}=0.039$ & & \\
\hline \multicolumn{6}{|l|}{ DIV } \\
\hline Intercept & 25.039 & 0.621 & & 40.33 & $<0.0001$ \\
\hline EReq & 0.040 & 0.006 & 0.275 & 6.80 & $<0.0001$ \\
\hline SMeq & 0.026 & 0.007 & 0.167 & 3.96 & $<0.0001$ \\
\hline GMeq & -0.015 & 0.007 & -0.096 & -2.14 & 0.0323 \\
\hline & $R=0.27$ & $R^{2}=0.07$ & Adjusted $R^{2}=0.068$ & & \\
\hline \multicolumn{6}{|l|}{ DEL } \\
\hline Intercept & 49.411 & 0.817 & & 60.48 & $<0.0001$ \\
\hline RAeq & 0.050 & 0.008 & 0.201 & 6.35 & $<0.0001$ \\
\hline & $R=0.20$ & $R^{2}=0.04$ & Adjusted $R^{2}=0.039$ & & \\
\hline \multicolumn{6}{|l|}{ CZN } \\
\hline Intercept & 12.448 & 0.433 & & 28.77 & $<0.0001$ \\
\hline EReq & 0.030 & 0.004 & 0.283 & 7.83 & $<0.0001$ \\
\hline SMeq & 0.0134 & 0.005 & 0.117 & 2.83 & 0.0048 \\
\hline ADeq & -0.014 & 0.005 & -0.124 & -2.74 & 0.0062 \\
\hline & $R=0.28$ & $R^{2}=0.77$ & Adjusted $R^{2}=0.073$ & & \\
\hline
\end{tabular}

ADeg, Adaptability EQ; CZN, Good social citizen; DEL, Delivery and Execution; DIV, Diversity/Transformation; EReq, Interpersonal EQ; GMeq, General Mood EQ; OD, Organisational Design; RAeq, Intraperonal EQ; SMeq, Stress Management EQ; STRT, Strategy; TOTALL, Leadership effectiveness overall; VBL, Values-based leadership

The model for TOTALL was significant $(F(4,964)=11.694 ; p<0.0001)$ with adjusted $\mathrm{R}^{2}=0.042$. RAeq had the largest positive influence on TOTALL $(\beta=0.189 ; t=3.22$; 
$p<0.01)$, followed by GMeq $(\beta=0.152 ; t=2.90 ; p<0.01)$. The effect of EReq was the least important, and had a negative relationship with TOTALL $(\beta=-0.116$; $t=-$ 2.84; $p<0.01$ ). However, the composite of three independent variables only explained $4.2 \%$ of the variability in the dependent variable.

For STRT, the regression $(R=0.28)$ was statistically significant $(F(4.965)=20.377$; $\mathrm{p}<0.0001)$. The variables RAeq $(\beta=0.198 ; t=3.43 ; p<0.01)$ and GMeq $(\beta=0.101$; $t=1.94 ; p<0.05)$ indicated a contribution that is significant for the prediction of STRT but only accounted for $7.4 \%$ of the variability in STRT. For VBL the regression $(R=0.22)$ was statistically significant $(F(3.963)=16.614 ; p<0.0001)$. The variables EReq $(\beta=0.204 ; t=5.60 ; p<0.01)$ and SMeq $(\beta=0.102 ; t=2.43 ; p<0.05)$ indicated a contribution that is significant for the prediction of $V B L$. However, they only accounted for $4.6 \%$ of the variability in $V B L$. In the case of $O D$, the regression $(R=0.20)$ was statistically significant $(F(2.958)=19.757 ; p<0.0001)$. The variables, EReq $(\beta=0.128 ; t=3.21 ; p<0.01)$ and GMeq $(\beta=0.097 ; t=2.44 ; p<0.05)$ indicated a contribution that was significant for the prediction of $O D$ but only accounted for $3.9 \%$ of the variability in $O D$.

The model for $D I V$ was significant $(F(1.957)=40.318$; $p<0.0001)$ with adjusted $R^{2}=$ 0.068 . EReq $(\beta=0.275 ; t=6.80 ; p<0.01)$ had the largest positive direct effect on $D I V$, followed by SMeq $(\beta=0.167 ; t=3.96 ; p<0.01)$. The effect of GMeq $(\beta=-$ $0.096 ; t=-2.14 ; p<0.05)$ was the least important, and had a negative relationship with DIV. The composite of three independent variables only explained $6.8 \%$ of the variability in DIV. For $D E L$, the regression $(\mathrm{R}=0.20)$ was statistically significant $(F(1.957)=4.0318 ; p<0.0001)$. Only one variable RAeq $(\beta=0.201 ; t=6.34 ; p<0.01)$ indicated a contribution that was significant for the prediction of $D E L$, but only accounted for $4 \%$ of the variability in $D E L$. Finally, for $C Z N$, the regression $(R=0.28)$ was statistically significant $(\mathrm{F}(3.954)=26.354 ; \mathrm{p}<0.0001)$. The variables $E$ Req $(\beta=$ 0.283; $t=7.83 ; p<0.01)$ and SMeq $(\beta=0.117 ; t=2.83 ; p<0.01)$ indicated a positive influence on CZN. ADeq's $(\beta=-0.124 ; t=-2.74 ; p<0.01)$ effect was least 
important and had a negative relationship with CZN. However, they only accounted for $7.3 \%$ of the variability in $A D e q$.

\section{Discussion}

The objective of this study was to investigate the relationship between emotional intelligence and leadership in a group of senior leaders in a South African financial services institution and to further understand whether EQ serves as a predictor of leadership for future leadership development purposes thereby strengthening the lead indicators of leadership effectiveness. The South African financial services organisation presents an interesting case for determining the relationship between emotional intelligence and leadership, given its specific organisationally embedded perspective of leadership. Leadership is viewed as a values-based, non-hierarchical construct and builds on the traditional models of leadership to include a more integrated, holistic and multi-level approach to leadership. These levels acknowledge the intrapersonal, interpersonal, organisational and societal implications for leadership. It is because of this inclusive orientation that biographical variables beyond age and gender, specifically linked to race, organisational position and tenure were not deemed relevant, not measured and therefore are not reflected here. Amongst the respondents 66.6\% $(n=629)$ were males and $35.4 \%(n=344)$ were females in executive or senior leadership positionswhich reflects a 2:1 gender ratio. This is characteristic of many global and South African organisations where despite significant advances in education and political participation, women remain underrepresented in leadership positions in politics and business (Pande \& Ford 2012).

Prior to the principal aims of the study being investigated, the reliability of the specific measuring instruments was assessed. The results indicated that the Cronbach alpha coefficients that were obtained from the Bar-On EQi (0.72 to 0.96) and the organisational multi-rater $(0.75$ to 0.94$)$ were satisfactory. These results support the findings obtained by Bar-On (2004) for the EQi. Owing to the multi-rater being an internally developed instrument, there was no external research to validate the reliability results. 
The subscales for both measuring instruments were highly interrelated, with the EQi showing intercorrelations ranging between 0.34 to 0.92 and the multi-rater's subscales ranging from 0.37 to 0.84 , which is supported by the research of Dawda and Hart (2000) as well as Ruderman (2001). It was concluded that the EQi and the multi-rater used, were satisfactory and were therefore regarded as reliable and valid for use in this study.

In order to fully understand the relationships between the variables of emotional intelligence and leadership it is critical to first highlight the results of the descriptive statistics. All the variables except SMeq and Adeq were significantly negatively skewed. Such distributions are typical of rating scales where many respondents rate/are rated near the top of the scale, with few rating/being rated negatively (McNeese 2008).This skewness results in several of the variables exhibiting significant non-normality. This has implications for the correlation analysis. As stated previously, owing to the non-normality of several of the variables in this study, the use of Pearson's correlation was not appropriate since this assumes normality of the data. Instead, the non-parametric alternative, Spearman's rank correlation was used (Babbie \& Mouton 2009). In considering the outcomes of the data and the fact that communication around the intent and purpose of the instrument to the raters was limited, it is possible that the multi-rater could have been misinterpreted as a performance appraisal on the 360 degree review. The senior leaders had the context around the use and application of the multi-rater, but in the nomination of raters this purpose may have been lost. With raters in the organisation having recently emerged from a turnaround, and then being asked to rate a senior leader on their "leadership performance", a possible explanation for these skewed results lies in the impact of the halo effect or rater bias (Thiry 2009). The halo effect occurs when a rater bases all ratings against a person's perceived positive qualities, features or traits. In other words, the rater has a generally positive impression of the person, and that impression skews all ratings on the 360-degree review. Rater bias could also manifest in the form of leniency (Gregory 1996; Thiry 2009). 
When interpreting results of the descriptive statistics further, the most skewed scales on the self-report EQi are those of self-regard and self-actualisation. Considering the fact that these are senior leaders in the organisation with a need for a good selfimage and sense of success at being in such positions through this turnaround, the conclusion one can draw is a positive impression or internalised halo effect on these subscales.

The main aim of the study, namely to assess whether there were any statistically significant relationships between emotional intelligence, its components and leadership, yielded significant results. The TOTAL EQ and TOTALL relationship emerged as slightly correlated $(r=0.15)$ which indicates that senior leaders who had higher levels of EQ also manifested signs of leadership effectiveness. Although the results reflect a relationship between the variables, they do not indicate a significant positive relationship between $E Q$ and leadership.

In line with some theoretical expectations that there appears to be a relationship between emotional intelligence and leadership effectiveness (Astrup \& McArthur 2011; Coetzee \& Schaap 2005; Gardner \& Stough 2002; Stuart \& Paquet 2001; Goleman 1995, 1998; Rosete \& Ciarrochi 2005), the correlations between the variables are significant but weak in that there is no evidence that any of the variables in emotional intelligence account for any of the leadership variables. EQ could influence the leadership effectiveness of a senior leader, but by the same token, leadership effectiveness could be a contributor to $E Q$ or alternatively a third external variable may have an influence over the relationship between EQ and leadership, whereby senior leaders in the organisation have had more exposure to tertiary qualifications, more leadership experience and/or more leadership development and therefore manifest signs of higher EQ and leadership effectiveness.

It was not possible to find previous research in South Africa or internationally, which utilised the same questionnaires and thus reported on the similar findings owing to the organisation-specific leadership instrument. Hence studies will be reported with 
the most similarities in terms of emotional intelligence and leadership as constructs. Studies by Kerr et al. (2006), Goleman (1995, 1998), Leban and Zulauf (2004), Rumchander and Martins (2014) and Ruderman et al. (2001) indicate a strong positive correlation between emotional intelligence scores and leadership effectiveness ratings whereby higher levels of certain EQ components appear to be connected to better leadership. Contrary to the results in this research, the studies of Antonakis (2004), Barbuto and Burbach (2006) and Brown et al. (2006) also reflect that emotional intelligence has no statistical significance in leadership effectiveness.

Supporting the findings of this research, there have also been studies conducted in a South African context by Astrup and McArthur (2011), Coetzee and Schaap (2005), Stuart and Paquet (2001) and Vrba (2007) that have explored the relationship between emotional intelligence and leadership. The conclusions drawn were that emotional intelligence relates significantly to leadership behaviour and the outcomes of leadership that are considered either effective or ineffective in a rapidly changing environment. It is essential, however, to distinguish between empirical research which reports significance between variables that is strong and therefore can serve as a predictive base and that which is weak and thus is not predictive in nature.

The results indicate that in this context, there is a relationship, albeit limited, between the dimensions of emotional intelligence and leadership. Correlational analysis indicates that there is a relationship (with a small affect) between all of the emotional intelligence scales and leadership scales except for those of EReq and TOTALL and SMeq and DEL, which reported no statistically significant relationship. This is somewhat surprising given that interpersonal relationships (EReq) are hypothesised to be core to the construct of leadership (TOTALL) as a relational construct within this study (Rost 1993). Furthermore, it would seem essential to have high levels of stress management EQ (SMeq) to face the pressures of organisational expectations on execution and delivery $(D E L)$ of performance targets. 
The strongest correlations between the leadership dimensions and EQ scales were TOTAL EQ and STRT ( $r=0.24 ; p=<0.01)$, RAeq with STRT $(r=0.26 ; p=<0.01)$ and EReq with CZN ( $r=0.24 ; p=<0.01)$. Lastly, GMeq lastly correlates significantly with STRT ( $r=0.24 ; p=<0.01)$. Carter (2009) explains the leadership variable of strategy in the organisational leadership philosophy as developing and contributing to strategy through accessing the community of leaders and being aware of the social, political and economic factors that influence the environment in which the organisation operates as well as providing a clear and compelling vision to inspire and align individual fulfilment and action. The total $E Q$ variable $(r=0.24 ; p=<0.01)$ as well as those of intrapersonal $(r=0.26 ; p=<0.01)$ and general mood EQ $(r=0.24 ; p=<0.01)$ correlated most strongly with strategy. When interpreting the relationship between these variables, a possible explanation is that those individuals who understand themselves and the way others feel are assertive, realistic, successful in realising the potential in situations, can solve problems and have an overall positive outlook on life. They can generally create an uplifting and positive atmosphere in the workplace. It makes sense that individuals who are grounded in themselves, have optimism and can engage with those around them would be effective at implementing strategies to facilitate organisational change initiatives (Ruderman et al. 2001; Stein \& Book 2006). This enables a firm ability to demonstrate the leadership requirements for being strategic and visionary.

The role of citizenship is also a central construct in the organisational leadership philosophy. According to Block (2008), leadership means that in addition to embracing their own humanity, which is the responsibility of every individual, the core task of leaders is to create the conditions for civic or institutional engagement. The leader's task is to structure the place and experience of these occasions to move the culture towards shared ownership. Being a good social citizen as a leadership variable is connected to making business decisions that are grounded in strong ethics and benefit the common good as well as participating and encouraging others to become active in community-based initiatives (Block 2008; Carter 2009; Kellerman 2012). This is possible to realise when an individual demonstrates responsibility and dependability along with good social skills. The findings of the 
relationship between interpersonal EQ (EReq) and being a good social citizen (CZN as $\mathrm{r}=0.24 ; p=<0.01$ ) demonstrate that an individual with strong interpersonal capacity can leverage, influence and harness the collective space effectively (Ruderman et al. 2001).

The diversity/transformation $(D I V)$ variable $(\mathrm{r}=0.21 ; p=<0.01)$ and values-based leadership $(V B L)$ variable $(r=0.20 ; p=<0.01)$ also correlated strongly with interpersonal EQ (EReq). When interpreting the relationship between these variables, potentially it might be understood as leaders that have empathy and have a strong sense of the value in terms of their social responsibility start to connect with their peers and subordinates in a way that enables a deeper understanding of the other, of their experiences, their challenges and the contributions they can make to organisational success (Barrett 2006). A leader that understands the value of embracing diversity and of acting with integrity is possibly able to have more effective relationships with those around them and thus be more successful in their leadership.

A sub-aim of the study was to establish whether emotional intelligence and its components could be viewed as predictors of leadership. The regression analysis shed more light on the relationship between EQ and leadership. The various EQ constructs were used as the independent variables and each of leadership constructs were in turn the dependent variables. The multiple regression analysis shows that very little of the variance of leadership can be predicted by emotional intelligence dimensions. The results show that RAeq, EReq and GMeq explain $4.2 \%$ of the variance in TOTALL. Whereas RAeq and GMeq showed a positive regression to TOTALL, EReq showed a negative regression. Whilst these are relatively small values that do not provide conclusive support of the researcher's argument, the regression models were nonetheless still significant. No other studies were found to support this finding. Whilst the regression analysis does indicate that there may be other factors (not included in this study) that may influence the predictive relationship between emotional intelligence and leadership it does point to a growing role that 
emotional intelligence plays as a predictor of effective leadership. An important factor in this study is the nature of the measurement of leadership. The multi-rater is an instrument that sets out to measure a meta-perspective of leadership more so than an individual perspective as highlighted by the organisational leadership paradigm. Hence only using emotional intelligence as a predictor of leadership effectiveness is counter-intuitive to what the multi-rater is trying to elicit.

The general aim of this research was to determine whether there is a relationship between the emotional intelligence of senior leaders and their leadership effectiveness. Although as discussed, the results do not indicate a predictive relationship between $E Q$ and leadership, the findings of this study do indicate that leaders in the South African financial services institution who demonstrate high levels of emotional intelligence also are regarded as effective leaders. Earlier in the article, it was mentioned that certain empirical findings have clearly established a relationship between the variables, while other research has just as empirically found no relationship. Although these results fail to support some of the more extreme claims of El proponents concerning the potential role of emotional intelligence in effective leadership, they did not rule out the possibly that El may play an important role. It is evident that this study in fact cannot clarify this relationship further but merely adds to the South African body of knowledge. Certainly this relationship between emotional intelligence and leadership may be far more complex than originally anticipated.

\section{Limitations and suggestions}

Although the research aims and empirical aims of this study were met, this study has some limitations, which should be taken into account. A definitive shortcoming of this research was the fact that it was conducted in one nationwide organisation with executive and senior leaders, which used a customised leadership measure. The results of the study are therefore not generalisable across other organisations nor to the wider organisation at lower levels of leadership. A second shortcoming was the limited sample statistics available to report, given the specific organisational 
leadership perspective that wanted to demonstrate inclusive, non-hierarchical, values-based characteristics and therefore did not include any biographical information beyond age and gender in the data collection. Thirdly, a cross-sectional design was used, with the result that no causal relationship between the variables could be determined over a period of time. The causal relationship was interpreted at a specific point in time. Furthermore, the use of self-ratings in both questionnaires is a huge limitation, as subjectivity can play a role in the results and therefore the findings of such a study. Finally, it is suggested that future studies should attempt to investigate the moderating variables affecting this relationship.

A recommendation for future use of the multi-rater in this organisational context for the purposes of leadership development would be to ensure appropriate communication and briefing around the purpose, intention and application of the measuring instrument thereby ensuring all raters are enabled and equipped in the role of being efficient raters. The Bar-On EQi is an individual self-report instrument reporting data rooted in an individualist orientation (Bar-on 1997), which, given the organisational leadership paradigm, may not be a fit-for-purpose measuring instrument. An emotional intelligence assessment grounded in a more collective measure may be more appropriate in future.

Future research should also include a broader sample of the organisation, other financial services organisations and possibly industries to test possible generalisations of this study for South African leadership. Investigation is also recommended for leadership ineffectiveness to determine whether the converse of the findings applies. Finally, longitudinal research, post the leadership development interventions identified, should be used in future to identify and isolate causal factors to ensure that environmental factors impacting on the data can be isolated and be meaningfully incorporated.

Further research definitively needs to be conducted in order to expand the knowledge of the possible influences or effects that emotional intelligence may have on leadership. For future studies it would be interesting to see the differences in 
leaders' self-perceptions versus those of others and/or to perhaps include a multirater for the emotional intelligence measurement as well.

\section{References}

Antonakis, J. 2004. On why emotional intelligence will not predict leadership Effectiveness beyond IQ or the "big five": an extension and rejoinder. Organizational Analysis 12(2):171-182.

Astrup, N. \& McArthur, B. 2011. The relationship between emotional intelligence and transformational leadership in information systems managers: an exploratory study. Management, Informatics and Research Design 132.

Avolio, B.J. 2007. Promoting more integrative strategies for leadership theorybuilding. American Psychologist 62(1):25-33.

Avolio, B.J., Walumbwa, F.O. \& Weber, T.J. 2009. Leadership: current theories, research and future directions. Annual Review of Psychology 60:421-449.

Babbie, E. \& Mouton, J. 2009. The practice of social research. Cape Town: Oxford University Press.

Barrett, R. 1998. Liberating the corporate soul: Building a visionary organization. Boston: Butterworth-Heinemann.

Bar-On, R. 1997. The emotional intelligence inventory (EQ-i): technical manual. Toronto: Multi-Health Systems.

Bar-On, R. 2002. Bar-On emotional quotient inventory (EQ-i): technical manual. Toronto: Multi-Health Systems.

Bar-On, R. 2004. The Bar-On emotional quotient inventory (EQ-i): rationale, description, and summary of psychometric properties, in Measuring emotional intelligence: common ground and controversy, edited by G. Geher. Hauppauge, NY: Nova Science:111-142.

Bar-On, R. 2006. The Bar-On model of emotional-social intelligence (ESI). Psicothema 18:13-25.

Bar-On, R. 2010. Emotional intelligence: an integral part of positive psychology. South African Journal of Psychology 40(1):54-86. 
Barbuto, J.E.\& Burbach, M.E. 2006. The emotional intelligence of transformational leaders: a field study of elected officials. The Journal of Social Psychology 146(1):51-64.

Bass, B.M. \& Bass, R. 2008. The Bass handbook of leadership: theory, research and managerial applications. New York: The Free Press.

Belsley, D.A., Kuh, E. \& Welsch, R.E. 1980. Regression diagnostics. New York: Wiley.

Bennis, W. \& Nanus, B. 2003. Leaders: strategies for taking charge. New York: Harper Collins.

Block, P. 2008. Community: the structure of belonging. San Francisco: BerrettKoehler.

Block, P. 2012. Reconstructing our idea of leadership. Available at: http://www.worldsviewacademy.com/blog/reconstructing-our-idea-ofleadership-by-peter-block/302/ (accessed on 25 March 2013).

Brown, F.W., Bryant, S.E. \& Reilly, M.D. 2006. Does emotional intelligence - as measured by the EQI - influence transformational leadership and/or desirable outcomes? Leadership and Organizational Development Journal 27(5):330-351.

Carter, H. 2009. Conscious leadership: articulating our conceptual model. Unpublished white paper.

Carter, H. \& Nussbaum, B. 2010. What do employees want from the 21st century organisation. Management Today 28:15-16.

Chauhan, S. 2012. The effects of financial liberalisation in emerging market economies. Master's dissertation, University of South Africa, Pretoria.

Coetzee, C. \& Schaap, P. 2005. The relationship between leadership behaviour, outcomes of leadership and emotional intelligence. South African Journal of Industrial Psychology 31(3).

Collins, J. 2001. Good to great. New York: Harper Business.

Crossan, M., Vera, D. \& Nanjad, L. 2008. Transcendent leadership: strategic leadership in dynamic environments. The Leadership Quarterly 19(5):569581. 
Dawda, D. \& Hart, S.D. 2000. Assessing emotional intelligence: reliability and validity of the Bar-On emotional quotient inventory $(E Q-i)$ in university students. Personality and Individual Differences 28:797-812.

Day, A.L. \& Carroll, S.A. 2008. Faking emotional intelligence (El): comparing response distortion on ability and trait-based El measures. Journal of Organizational Behavior 29(6):761-784.

De Bettignies, H.C. \& Lepineux, F. 2009. Can multinational corporations afford to ignore the global common good? Business and society review 114(2):153182.

De Miranda, L.C.S. 2011. The relationship between emotional intelligence and leadership effectiveness with an emphasis on corporate culture in a consumer goods organization. Master's dissertation, University of South Africa, Pretoria.

Drucker, P.F. 2008. Managing oneself. Boston: Harvard Business School Press.

Dulewicz, V. \& Higgs, M. 2000. Emotional intelligence a review and evaluation study. Journal of Managerial Psychology 15(4):341-372.

Financial Mail. 2006. The worst is over, 9 June,18-23.

Gardner, L. \& Stough, C. 2002. Examining the relationship between leadership and emotional intelligence in senior level managers. Leadership and Organisation Development Journal 23(2):68-78.

Glenn, J.C., Gordon, T.J. \& Florescu, E. 2010. The state of the future 2010. Editura Universitară:45.

Goleman, D. 1995. Emotional intelligence. New York: Bantum.

Goleman, D. 1998. Working with emotional intelligence. New York: Bantam.

Goleman, D., Boyatzis, R. \& McKee, A. 2002. Primal leadership: realizing the power of emotional intelligence. Boston: Harvard Business School Press.

Gitsham, M. \& Pegg, M. 2012. Leadership in a rapidly changing world: how business leaders are reframing success. Ashridge Business School.

Gregory, R.J. 1996. Psychological testing. $2^{\text {nd }}$ edition. Boston: Allyn \& Bacon.

Hair, J.F. Jr, Tatham, R.L., Black, W.C., Anderson, R.E. \& Black, W. 1998. Multivariate data analysis. $5^{\text {th }}$ edition. Upper Saddle River, NJ: Prentice-Hall. 
Hamel, G. \& Breen, B. 2007. The future of management. Harvard Business School Press.

Hofmann, D.A., Morgeson, F.P. \& Gerras, S. 2003. Climate as a moderator of the relationship between LMX and content specific citizenship: Safety climate as an exemplar. Journal of Applied Psychology 88:170-178.

Kellerman, B. 2012. The end of leadership. New York: Harper Collins.

Kerr, R., Gavin, J., Heaton, N. \& Boyle, E. 2005. Emotional intelligence and leadership effectiveness. Leadership and Organization Development Journal 27(4):265-279.

Leadership Magazine. 2009. Tom Boardman: transformation begins with leaders. 298:14-18.

Leban, W. \& Zulauf, C. 2004. Linking emotional intelligence abilities and transformational leadership styles. The Leadership and Organization Development Journa, 25(7):554-564.

Leslie, K. \& Canwell, A. 2010. Leadership at all levels: leading public sector organisations in an age of austerity. European Management Journal 28(4): 297-305.

Matthews, G., Zeidner, M. \& Roberts, R.D. 2002. Emotional intelligence: science and myth. Cambridge, MA: MIT Press.

Mayer, J.D. 1999. Emotional intelligence: popular or scientific psychology. APA Monitor 30(8):50.

McNeese, W. 2008. Are skewness and kurtosis useful statistics? BPI Consulting, LLC, April. Available at: http://www.spcforexcel.com/are-skewness-andkurtosis-useful-statistics (accessed on 11 September 2013).

Mills, L.B. 2009. A meta-analysis of the relationship between emotional intelligence and effective leadership. Journal of Curriculum and Instruction 3:22-38.

Mintzberg, H. 2009. Rebuilding companies as communities. Harvard Business Review 87:40-143.

Newsome, S., Day, A.L. \& Catano, V.M. 2000. Assessing the predictive validity of emotional intelligence. Personality and Individual Differences, 29(6):10051016.

Northouse, P.G. 2012. Leadership: theory and practice. $6^{\text {th }}$ edition. New York: Sage. 
Ford, D., \& Pande, R. 2012. Gender Quotas and Female Leadership. Washington DC, World Bank: World Development Report. Available at: https://openknowledge.worldbank.org/handle/10986/9120 (accesed on 25 June 2014).

Palmer, B., Walls, M., Burgess, Z. \& Stough, C. 2001. Emotional intelligence and effective leadership. Leadership and Organization Development Journal 22(1): 5-10.

Rosete, D. \& Ciarrochi, J. 2005. Emotional intelligence and its relationship to workplace performance outcomes of leadership effectiveness. Leadership and Organization Development Journal 26(5):388-399.

Rost, J.C. 1993. Leadership for the twenty-first century. Westport, CT: Greenwood.

Ramchunder, Y. \& Martins, N. 2014. The role of self-efficacy, emotional intelligence and leadership style as attributes of leadership effectiveness: original research. SA Journal of Industrial Psychology 40(1):1-11.

Ruderman, M.N., Hannum, K., Leslie, J.B. \& Steed, J.L. 2001. Leadership skills and emotional intelligence (manuscript). Greensboro, NC: Center for Creative Leadership.

Salovey, P. \& Mayer, J.D. 1990. Emotional intelligence. Imagination, Cognition and Personality 9:185-211.

StatSoft Inc. 2011. STATISTICA®.Version 10.0 [computer program]. Tulsa, OK StatSoft Inc.

Stein, S.J. \& Book, H.E. 2006. The EQ edge: emotional intelligence and your success (revised \& updated). Mississauga, Ontario: Wiley.

Stuart, A. \& Paquet, A. (2001). Emotional intelligence as a determinant of leadership potential. Journal of Industrial Psychology 27(3):30-34.

Struwig, H. 2012. Personal communication on the 18 November.

Tavakol, M. \& Dennik, R. 2011. Making sense of Cronbach's alpha. International Journal of Medical Education 2:53-55.

Thiry, K.J. 2009. Factors that affect peer rater accuracy in multi-rater feedback systems. Doctoral dissertation. Minneapolis: Capella University, 
Van Oosten, E. B. 2013. The Impact of Emotional Intelligence and Executive Coaching on Leader Effectiveness. Doctoral dissertation. Ohio: Case Western Reserve University.

Veldsman, T.H. 2002. Into the people effectiveness arena: navigating between chaos and order. Randburg: Knowledge Resources.

Vrba, M. 2007. Emotional intelligence skills and leadership behaviour in a sample of South African first-line managers. Management Dynamics 16(2):25-35.

Welfens, P.J.J. 2009. Financial markets and instability: theory and policy issues. Heidelberg \& New York: Springer.

Welfens, P.J. 2011. From the transatlantic banking crisis to the euro crisis? International Economics and Economic Policy 8(1):15-29.

Wheatley, M. 2006. Leadership lessons from the real world. Leader to Leader 41:16. www.valuescentre.com (accessed on on 30 July 2012). 


\section{CHAPTER 4: CONCLUSIONS, LIMITATIONS AND RECOMMENDATIONS}

The previous chapter presented the results of the research in the form of an article. This chapter provides an overview of the research. Firstly, conclusions will be drawn and the limitations of study discussed. Finally, recommendations will be made.

\subsection{CONCLUSIONS}

The research focused on investigating the relationship between emotional intelligence and leadership. Research conclusions drawn from the literature review and the empirical study for each of the research aims, as stated in section 1.3 in chapter 1 , will be formulated below.

\subsubsection{Literature review}

The specific literature aims were to conceptualise the constructs of emotional intelligence and leadership from the organisational perspective, which formed part of the study, and to investigate the theoretical relationship between them. This aim was achieved by means of the literature review in chapter 2 of this dissertation.

There are both mental ability models and mixed models of emotional intelligence. The mental ability model of Mayer and Salovey (1997) focuses on emotions themselves and their engagement with thoughts. The mixed models, represented by Bar-On (1997) and Goleman (1995), treat mental abilities and a diversity of other characteristics as mutually exclusive.

Emotional intelligence was defined as "an array of non-cognitive capabilities, competencies and skills that influence one's ability to succeed in coping with environmental demands and pressures" (Bar-On 1997:14). Bar-On (1997) expressly operationalised emotional intelligence according to 15 conceptual components (emotional skills) pertaining to five specific dimensions of emotional and social 
intelligence, namely intrapersonal $E Q$, interpersonal $E Q$, stress management $E Q$, adaptability EQ and general mood EQ.

Emotional intelligence is seen as an essential factor in determining one's ability to succeed in life and is understood to directly influence one's state of mind or overall degree of emotional health (Bar-On 1997). Based on these insights, Stuart and Paquet (2001:30) postulate that "emotional health should also have some impact on the presence or absence of leadership ability".

Leadership was conceptualised as a vast and broad construct with no uniformly accepted definition in the literature and so people are unable to identify it correctly when they see it manifesting. In their review of leadership literature, Bennis and Nanus (2003) noted that academic analysis has generated hundreds of definitions of leadership.

In this study, leadership was conceptualised on the basis of the South African financial services organisational paradigm as a process with a relational space, as its essential nature. There is growing evidence for this shared or collective leadership in organisations as hierarchical levels are dismantled and team-based structures are explored (Avolio et al. 2009). Shared leadership generally is viewed "as a process versus a person engaging multiple members of the team" (Avolio et al. 2009:431). This concept of leadership means that in addition to embracing their own humanity, which is the responsibility of every individual, the core task of leaders is to create the conditions for civic or institutional engagement (Block 2008). The leader's task is to structure the place and experience of these occasions to move the culture towards shared ownership. According to Avolio et al. (2009), shared leadership is the property of the whole system and not of individuals, effectiveness in leadership is therefore the result of the connections and relationships between the parts and not because of any one part of the system like the individual leader.

The literature researched is supportive of the notion of a relationship between emotional intelligence and leadership (Drucker 2008, Gardner \& Stough 2002; 
Goleman 1995, 1998; Palmer et al. 2001; Rosete \& Ciarrochi 2005), but there is also research that found that the state of empirical evidence for the relationship between El and leadership remains weak even after 15 years (Antonakis 2004). Further research reported no statistical significance between emotional intelligence and leadership effectiveness (Barbuto \& Burbach 2006; Brown et al. 2006). Thus the conclusion in the literature is not conclusive around the relationship between emotional intelligence and leadership.

\subsubsection{Empirical study}

The objective of the study was to determine the relationship between emotional intelligence and leadership. The additional empirical aim of the study was to establish whether emotional intelligence and its components could be viewed as predictors of leadership. This was achieved in chapter 3 by means of reporting and discussing the results in the article. The following conclusions can be drawn from the results and can be regarded as specific to the financial services industry, particularly the organisation that was studied.

It was concluded that the measuring instruments namely, the Bar-On EQi and the organisation-specific multi-rater used were regarded as reliable and valid for use in this study.

All the variables except SMeq and ADeq were significantly negatively skewed. Such distributions are typical of rating scales where many respondents rate/are rated near the top of the scale, with few rating/being rated negatively. This skewness results in several of the variables exhibiting significant non-normality. Given the non-normality of several of the variables in this study, the use of Pearson's correlation was not appropriate since this assumes normality of the data. Instead, the non-parametric alternative, Spearman's rank correlation, was used (Babbie \& Mouton 2009).

Correlational analysis indicated that there was a relationship (with a small effect) between all of the emotional intelligence scales and leadership scales except for those of EReq and TOTALL and SMeq and DEL, which reported no statistically 
significant relationship. The results indicate that there was a relationship, albeit limited, between the dimensions of emotional intelligence and leadership.

The multiple regression analysis showed that, very little of the variance of leadership can be predicted by emotional intelligence dimensions. The results show that RAeq, EReq and GMeq explain $4.2 \%$ of the variance in TOTALL. Whereas RAeq and GMeq showed a positive regression to TOTALL, EReq showed a negative regression. Intrapersonal EQ had the largest positive influence on overall leadership, followed by general mood EQ. The effect of interpersonal EQ was the least important, and had a negative relationship with overall leadership.

The central hypothesis of the research (as stated in section 1.4.3), that there is a positive and significant relationship between emotional intelligence and leadership among leaders in the financial services organisation should be accepted partially because a significant relationship was found. The TOTAL EQ and TOTALL relationship emerged as slightly correlated $(r=0.15 ; p=<0.01)$, which indicates that senior leaders with higher levels of $E Q$ also manifested signs of leadership effectiveness. Although the results reflect a relationship between the variables they do not indicate a predictive relationship between EQ and leadership.

No statistically significant relationships emerged between EReq and TOTALL $(r=0.06)$, or between SMeq and DEL $(r=0.06)$. Almost all the correlations were significant, including many with very low correlation coefficients. This is a result of the large sample size (Cohen 1977). Hence effect size needs to be considered to decipher which correlations are really important.

\section{$4.2 \quad$ LIMITATIONS}

This research study was not without limitations. The limitations of the research are discussed below with regard to the literature review and the empirical study. 


\subsubsection{Literature review}

- Studies around the relationship between emotional intelligence and leadership are available but have, like the literature in the same field, contradictory findings. The disagreement of such information limited the researcher in determining a theoretical relationship beyond the speculation, which is currently available.

- Only a few South African studies have been conducted in this field, and the studies that are available span a range of different applications and cut across different measuring instruments for emotional intelligence and leadership.

- A wide range of leadership models and dimensions exist in the literature, which added to the complexity of conceptualising the organisational leadership construct in this study.

\subsubsection{Empirical study}

- A definitive shortcoming of this research was the fact that it was conducted in one nationwide organisation, which used a customised leadership measure. The rationale for selecting this organisation specifically was to contribute to the existing leadership interventions taking place, thereby affording the researcher the opportunity to test the potential of the relationship between emotional intelligence and leadership. The results of the study are therefore not generalisable across other organisations. Future studies need to look more broadly across organisations and industries before the results can be made more generalisable and the requirements of external validity can be met.

- Another limitation was the limited sample statistics available to report, given the specific organisational leadership perspective, that wanted to demonstrate inclusive, non-hierarchical, values-based characteristics and therefore did not include any biographical information beyond age and gender in the data collection.

- A very large sample like the one in this study would have the tendency to indicate statistical significance in all instances, even where practical significance is not indicated. 
- The Bar-On EQi used in this study was a self-report questionnaire. Self-reported abilities and traits rely heavily on a person's self-understanding. If a person's selfconcept is inaccurate, which can be the case, the self-report measures give information concerning the person's self-concept per se instead of the actual ability or trait in question.

- In the empirical study, it was found that the leadership questionnaire, although demonstrating reliability and validity, might have been exposed to rater bias and/or the halo effect, which would then have influenced the data. This was perhaps due to the "other" raters not having sufficient context around completing the multi-rater.

- The skewness of the multi-rater results limited the overall findings of the study.

- The instruments used in this study may have inherently been paradoxical measures given a misalignment between the organisational leadership philosophy and practical intentions behind the measuring instruments.

- A cross-sectional design was used with the result that no causal relationship between the variables could be determined over a period of time. The causal relationship was interpreted at a specific point in time.

- The number of years' experience in a senior leadership position may also have influenced this study but could not be accounted for. It is suggested that future studies should investigate the moderating variables affecting the relationship between emotional intelligence and leadership.

\subsection{RECOMMENDATIONS}

This study generated several organisational application suggestions as well as suggestions for future research. The following recommendations, based on the results of this study, can be formulated for the South African financial services organisation:

- In this study, the leadership multi-rater used in the analysis was constructed by the organisation for specific organisational application. During the analysis it was 
discovered that there was relatively significant skewness of the data. It is therefore recommended that understanding of the instrument and behaviours being measured be clear to all completing the assessment. A recommendation for future use of the multi-rater in this organisational context for the purposes of leadership development would be to ensure appropriate communication and briefing around the purpose, intention and application of the measuring instrument, thereby ensuring all raters are enabled and equipped in the role of being good raters.

- The Bar-On EQi is an individual self-report instrument reporting data rooted in an individualist orientation (Bar-on 1997) which, given the organisational leadership paradigm, may not be a fit for purpose measuring instrument. An emotional intelligence assessment grounded in a more collective measure may be more appropriate in future.

- Future research should also include a broader sample of the organisation, other financial services organisations and possibly industries to test possible generalisations of this study for South African leadership to allow for a more comprehensive comparison of the relationship between emotional intelligence and leadership.

- Investigation is also recommended for leadership ineffectiveness to determine whether the converse of the findings applies.

- Longitudinal research, post the leadership development interventions identified, should be used in future to identify and isolate causal factors, in order to ensure that environmental factors impacting on the data can be isolated and be meaningfully incorporated.

- It is recommended that the organisation consider evaluating current leadership development programmes to include aspects around emotional intelligence without over emphasizing the predictive value of El for leadership. This will potentially enable leaders with lower levels of emotional intelligence to enhance their motivation and self-confidence and to lead their subordinates in a more constructive way.

- It is recommended that further studies be conducted in the area of leadership effectiveness in order to understand the construct more deeply, ascertain the 
challenges and pitfalls associated with it and then appropriately use it as part of research into relationships with other variables.

Further research within the field of industrial and organisational psychology clearly needs to be conducted to expand the knowledge and understanding about the possible influences or effects emotional intelligence may have on leadership because this is a complex relationship that needs further validation.

\subsection{CHAPTER SUMMARY}

In this chapter the conclusions, limitations and recommendations of the research were discussed on the basis of the aims of the study, as presented in section 1.3 of chapter 1 . The literature aims as well as the empirical aims of the study were addressed in terms of conclusions drawn and limitations observed. Based on the findings, recommendations were made for further research. 


\section{REFERENCES}

Anand, R. 2010. Emotional intelligence and its relationship with leadership practices.

International Journal of Business and Management 5(2):65-76.

Antonakis, J. 2003. Why "emotional intelligence" does not predict leadership effectiveness: a comment on Prati, Douglas, Ferris, Ammeter and Buckley. The International Journal of Organizational Analysis 11:355-361.

Antonakis, J. 2004. On why emotional intelligence will not predict leadership effectiveness beyond IQ or the "big five": an extension and rejoinder. Organizational Analysis 12(2):171-182.

Astrup, N. \& McArthur, B. 2011. The relationship between emotional intelligence and transformational leadership in information systems managers: an exploratory study. Management, Informatics and Research Design:132.

Avolio, B.J. 2007. Promoting more integrative strategies for leadership theorybuilding. American Psychologist 62(1):25-33.

Avolio, B.J., Luthans, F. \& Walumba, F.O. 2004. Authentic leadership: theory building for veritable sustained performance. Working paper. Gallup Leadership Institute, University of Nebraska-Lincoln.

Avolio, B.J., Walumbwa, F.O. \& Weber, T.J. 2009. Leadership: current theories, research and future directions. Annual Review of Psychology 60:421-449.

Babbie, E. \& Mouton, J. 2009. The practice of social research. Cape Town: Oxford University Press.

Barrett, R. 1998. Liberating the corporate soul: Building a visionary organization. Boston: Butterworth-Heinemann.

Barrett, R. 2006. Building a values-driven organization: a whole system approach to cultural transformation. Burlington, MA: Butterworth Heinemann.

Bar-On, R. 1997. The emotional intelligence inventory (EQ-I): technical manual. Toronto: Multi-Health Systems.

Bar-On, R. 2002. Bar-On emotional quotient inventory (EQ-I): technical manual. Toronto: Multi-Health Systems. 
Bar-On, R. 2004. The Bar-On emotional quotient inventory (EQ-i): rationale, description, and summary of psychometric properties. Measuring emotional intelligence: common ground and controversy. edited by G. Geher. Hauppauge, NY: Nova Science:111-142.

Bar-On, R. 2005. The impact of emotional intelligence on subjective well-being. Perspectives in Education 23(2):41-62.

Bar-On, R. 2006. The Bar-On model of emotional-social intelligence (ESI). Psicothema 18:13-25.

Bar-On, R. 2007. How important is it to educate people to be emotionally intelligent, and canit be done? in Educating people to be emotionally intelligent, edited by R. Bar-On, J.G. Maree \& M. Elias. Westport, CT: Praeger:1-14.

Bar-On, R. 2010. Emotional intelligence: an integral part of positive psychology. South African Journal of Psychology 40(1):54-86.

Barbuto, J.E. \& Burbach, M.E. 2006. The emotional intelligence of transformational leaders: a field study of elected officials. The Journal of Social Psychology 146(1):51-64.

Bass, B.M. 1985. Leadership and performance beyond expectations. New York: Free Press.

Bass, B.M. 1990. Handbook of leadership: theory, research and managerial applications. $3^{\text {rd }}$ edition. New York: Free Press.

Bass, B.M. \& Avolio, B.J. 1994. Improving organizational effectiveness through transformational leadership. Thousand Oaks, CA: Sage.

Bass, B.M. \& Bass, R. 2008. The Bass handbook of leadership: theory, research and managerial applications. New York: Free Press.

Belsley, D.A., Kuh, E. \& Welsch, R.E. 1980. Regression diagnostics. New York: Wiley.

Becker, T. 2003. Is emotional intelligence a viable concept? The Academy of Management Review 28(2):192-195.

Bennis, W. \& Nanus, B. 2003. Leaders: strategies for taking charge. New York: Harper Collins.

Block, P. 2008. Community: the structure of belonging. San Francisco: BerrettKoehler. 
Block, P. 2012. Reconstructing our idea of leadership. Available at: http://www.worldsviewacademy.com/blog/reconstructing-our-idea-ofleadership-by-peter-block/302/ (accessed on on 25 March 2013).

Boyatzis, R.E. 1994. Stimulating self-directed learning through the managerial assessment and development course. Journal of Management Education 18(3).

Boyatzis, R.E. 2001. How and why individuals are able to develop emotional intelligence, in The emotionally intelligent workplace: how to select for, measure, and improve emotional intelligence in individuals, groups, and organizations, edited by C. Cherniss and D. Goleman, San Francisco, CA: Jossey_Bass: 234-253..

Boyatzis, R.E. 2009. Competencies as a behavioral approach to emotional intelligence. Journal of Management Development 28(9):749-770.

Boyatzis, R.E., Goleman, D. \& Rhee, K. 1999. Clustering competence in emotional intelligence: insights from the emotional competence inventory $(\mathrm{ECl})$, in Handbook of emotional intelligence, edited by R. Bar-On and J.D. Parker. San Francisco, CA: Jossey Bass.

Brackett, M.A., Rivers, S.E. \& Salovey, P. 2011. Emotional intelligence: implications for personal, social, academic, and workplace success. Social and Personality Psychology Compass 5(1):88-103.

Bradberry, T. \& Greaves, J. 2003. Emotional intelligence quickbook: everything you need to know, San Diego, CA: Talent Smart.

Brown, F.W., Bryant, S.E. \& Reilly, M.D. 2006. Does emotional intelligence - as measured by the EQI - influence transformational leadership and/or desirable outcomes? Leadership and Organizational Development Journal 27(5):330-351.

Burns, M.J. 1978. Leadership. New York: Harper \& Row.

Caruso, D.R., Mayer, J.D. \& Salovey, P. 2002. Emotional intelligence and emotional leadership, in Multiple intelligences and leadership, edited by F.J. Pirozzolo. S.E. Murphy and R.E. Riggio. New Jersey: Lawrence Erlbaum.

Carter, H. 2009. Conscious leadership: articulating our conceptual model. Unpublished white paper. 
Carter, H. 2010. Personal communication, 20 November.

Carter, H. \& Nussbaum, B. 2010. What do employees want from the 21st century organisation. Management Today 28:15-16.

Cascio, W.F. 2001. Knowledge creation for practical solutions appropriate to the changing world of work. South African Journal of Industrial Psychology 27(4): 14-16.

Cashman, K. 1998. Leadership from inside out. Provo, UT: Executive Excellence.

Cavallo, K. \& Brienza, D. 2000. Emotional competence and leadership excellence at Johnson \& Johnson: the emotional intelligence and leadership study. Paper presented at the Meeting of the Consortium for Research on Emotional Intelligence in Organizations, Cambridge, Massachusetts, 3 November.

Chaudhry, A.A. \& Saif, A. 2012. Presence and potential of emotional intelligence (EI) in organizational settings. African Journal of Business Management 6(20): 6117-6122.

Chauhan, S. 2012. The effects of financial liberalisation in emerging market economies. Master's dissertation, University of South Africa, Pretoria.

Coetzee, C. \& Schaap, P. 2005. The relationship between leadership behaviour, outcomes of leadership and emotional intelligence. South African Journal of Industrial Psychology 31(3).

Collier, J. \& Esteban, R. 2000. Systemic leadership: ethical and effective. The Leadership and Organisation Development Journal 21(4):207-215.

Collins, J. 2001. Good to great. New York: Harper Business.

Collins, J.C. \& Porras J.I. 2000. Built to last: successful habits of visionary companies. London: Random House.

Conte, J. M. 2005. A review and critique of emotional intelligence measures. Journal of Organizational Behavior 26(4), 433-440.

Crossan, M., Vera, D. \& Nanjad, L. 2008. Transcendent leadership: strategic leadership in dynamic environments. The Leadership Quarterly 19(5):569581.

Dawda, D. \& Hart, S.D. 2000. Assessing emotional intelligence: reliability and validity of the Bar-On emotional quotient inventory $(E Q-i)$ in university students. Personality and Individual Differences 28:797-812. 
Day, A.L. \& Carroll, S.A. 2008. Faking emotional intelligence (El): comparing response distortion on ability and trait-based El measures. Journal of Organizational Behavior 29(6):761-784.

De Bettignies, H.C. \& Lepineux, F. 2009. Can multinational corporations afford to ignore the global common good? Business and Society Review 114(2):153182.

De Miranda, L.C.S. 2011. The relationship between emotional intelligence and leadership effectiveness with an emphasis on corporate culture in a consumer goods organization. Master's dissertation, University of South Africa, Pretoria.

Drucker, P.F. 2008. Managing oneself. Boston: Harvard Business School Press.

Dulewicz, V. \& Higgs, M. 2000. Emotional intelligence a review and evaluation study. Journal of Managerial Psychology 15(4):341-372.

Elliott, H. 2003. Emotional intelligence-based leadership. Otago Management Graduate Review 1:23-36.

Emmerling, R.J. \& Goleman, D. 2003. Emotional intelligence: issues and common misunderstandings. Issues in Emotional Intelligence 1(1):1-32.

Epstein, S. 1998. Constructive thinking: the key to emotional intelligence. Westport, CT: Praeger.

Financial Mail. 2006. The worst is over, 9 June, 18-23.

Fernández-Berrocal, P.\& Extremera, N. 2006. Emotional intelligence: a theoretical and empirical review of its first 15 years of history. Psicothema 18(Suplemento):7-12.

Freedman, J. \& Everett, T. 2010. The business case for emotional intelligence. White Paper: Six Seconds.

Gardner, H. 1983. Frames of mind: the theory of multiple intelligences. New York: Basic Books.

Gardner, H. \& Hatch, T. 1989. Multiple intelligences go to school: educational implications of the theory of multiple intelligences. Educational Researcher:410.

Gardner, L. \& Stough, C. 2002. Examining the relationship between leadership and 
emotional intelligence in senior level managers. Leadership and Organisation Development Journal 23(2):68-78.

Glenn, J.C., Gordon, T.J. \& Florescu, E. 2010. The state of the future 2010. EdituraUniversitară 45.

Goleman, D. 1995. Emotional intelligence. New York: Bantum.

Goleman, D. 1996. Emotional intelligence. London: Bloomsbury.

Goleman, D. 1997. Healing emotions. Boston: Shambhala.

Goleman, D. 1998. Working with emotional intelligence. New York: Bantam.

Goleman, D. 2001. Emotional intelligence: issues in paradigm building, in

The emotionally intelligent workplace, edited by C. Cherniss \& D. Goleman. San Francisco, CA: Jossey-Bass: 13-26.

Goleman, D. 2002. Leading resonant teams. Leader to Leader 25:24-30.

Goleman, D. 2004. Emotional intelligence, why it can matter more than IQ \& working with emotional intelligence: omnibus. London: Bloomsbury.

Goleman, D., Boyatzis, R. \& McKee, A. 2002. Primal leadership: learning to lead with emotional intelligence. Boston: Harvard Business School Press.

Gladwell, M. 2002. The tipping point: how little things can make a big difference. New York: Back Bay Books, Little Brown.

Gitsham, M. \& Pegg, M. 2012. Leadership in a rapidly changing world: how business leaders are reframing success. Ashridge Business School.

Glenn, J.C., Gordon, T.J. \& Florescu, E. 2010. The state of the future 2010. EdituraUniversitară:45.

Gregory, R.J. 1996. Psychological testing. $2^{\text {nd }}$ edition. Boston: Allyn \& Bacon.

Grint, K. 2005. Leadership: limits and possibilities. Hong Kong: Palgrave Macmillan.

Guba, E.G. (ed.). 1990. The paradigm dialogue. Newbury Park, CA: Sage.

Hair, J.F. Jr, Tatham, R.L., Black, W.C., Anderson, R.E. \& Black, W. 1998. Multivariate dataanalysis. 5th edition. Upper Saddle River, NJ: Prentice Hall.

Hamel, G. \& Breen, B. 2007. The future of management. Boston: Harvard Business School Press.

Handy, C. 1997. The citizen corporation. Harvard Business Review 75(5):26-27. 
Harms, P. D., \& Credé, M. 2010. Emotional intelligence and transformational and transactional leadership: A meta-analysis. Journal of Leadership \& Organizational Studies 17(1), 5-17.

Hedlund, J. \& Sternberg, R.J. 2000. Too many intelligences? Integrating social, emotional, and practical intelligence, in Handbook of emotional intelligence, edited by R. Bar-On \& J.D.A. Parker. San Francisco, CA: Jossey-Bass: 13668.

Higgs, M. 2003. How can we make sense of leadership in the $21^{\text {st }}$ century? Leadership and Organisational Development Journal 25(5):273-284.

Hofmann, D.A., Morgeson, F.P. \& Gerras, S. 2003. Climate as a moderator of the relationship between LMX and content specific citizenship: safety climate as an

exemplar. Journal of Applied Psychology 88:170-178.

http://www.dalailama.com/news/post/809-stand-up-be-the-change (accessed on 14 July 2012).

http://www.nytimes.com/2009/01/20/us/politics/20textobama.html?_r=1\&src=tp\&pag ewanted=all (accessed on 14 July 2012).

Ivey, A.E., Ivey, M.B. \& Simek-Morgan, L. 1997. Counselling and psychotherapy: a multicultural perspective. London: Allyn \& Bacon.

Kahane, A. 2010. Power and love: a theory and practice of social change. San Francisco, CA: Berrett-Koehler.

Kellerman, B. 2012. The end of leadership. New York: HarperCollins.

Kerr, R., Gavin, J., Heaton, N. \& Boyle, E. 2005. Emotional intelligence and leadership effectiveness. Leadership and Organization Development Journal 27(4):265-279.

Kets de Vries, M.F.R. 1993. Leaders, fools and imposters. San Francisco: JosseyBass.

Kets de Vries, M.F.R. 2001. The leadership mystique. London: Financial Times/Prentice Hall.

Leadership Magazine. 2009. Tom Boardman: transformation begins with leaders 298: 14-18. 
Leban, W. \& Zulauf, C. 2004. Linking emotional intelligence abilities and transformational leadership styles. The Leadership and Organization Development Journal 25(7):554-564.

Leslie, K. \& Canwell, A. 2010. Leadership at all levels: leading public sector organisations in an age of austerity. European Management Journal 28(4): 297-305.

Locke, E.A. 2005. Why emotional intelligence is an invalid concept. Journal of Organizational Behavior 26(4):425-431.

Matthews, G., Zeidner, M. \& Roberts, R.D. 2002. Emotional intelligence: science and myth. Cambridge, MA: MIT Press.

Matthews, G., Roberts, R.D. \& Zeidner, M. 2004. Seven myths about emotional intelligence. Psychological Inquiry 15:179-196.

Mayer, J.D. 1999. Emotional intelligence: popular or scientific psychology? APA Monitor 30(8):50.

Mayer, J.D. 2001. A field guide to emotional intelligence, in Emotional intelligence in everyday life: a scientific inquiry, edited by J. Ciarrochi, J.P. Forgas \& J.D. Mayer.

New York: Psychology Press:3-24.

Mayer, J.D. \& Salovey, P. 1997. What is emotional intelligence? in Emotional development and emotional intelligence, edited by P. Salovey \& D.J. Sluyter. New York: Basic Books:3-31.

McLeod, J. 2003. The humanistic paradigm, in Handbook of counselling psychology, edited by R. Woolfe, W. Dryden \& S. Strawbridge. $2^{\text {nd }}$ edition. London: Sage:140-160.

McNeese, W. 2008. Are the skewness and kurtosis useful statistics? BPI Consulting, LLC. April. Available at:http://www.spcforexcel.com/are-skewness-andkurtosis-useful-statistics (accessed on 11 September 2013).

Meyer, W., Moore, C. \& Viljoen, H. 2003. Personology. Personology: From Individual to Ecosystem 3:2-21.

Mills, L.B. 2009. A meta-analysis of the relationship between emotional intelligence and effective leadership. Journal of Curriculum and Instruction 3:22-38. 
Mintzberg, H. 2009. Rebuilding companies as communities. Harvard Business Review 87:40-143.

Mouton, J. \& Marais, H.C. 1991. Basic concepts in the methodology of the social sciences. Pretoria: Human Sciences Research Council.

Newsome, S., Day, A.L. \& Catano, V.M. 2000. Assessing the predictive validity of emotional intelligence. Personality and Individual Differences 29(6):10051016.

Northouse, P.G. 2012. Leadership: theory and practice. $6^{\text {th }}$ edition. New York: Sage.

Nussbaum, B. 2010. Personal communication on 7 September.

Palmer, B., Walls, M., Burgess, Z. \& Stough, C. 2001. Emotional intelligence and effective leadership. Leadership and Organization Development Journal 22(1): 5-10.

Parry, K.W. \& Proctor-Thomson, S.B. 2002. Perceived integrity of transformational leaders in organizational settings. Journal of Business Ethics 35:75-96.

Roberts, R.D., Zeidner, M. \& Matthews, G. 2001. Does emotional intelligence meet traditionalstandards for an intelligence? Some new data and conclusions. Emotion 1:196-231.

Rosete, D. \& Ciarrochi, J. 2005. Emotional intelligence and its relationship to workplace performance outcomes of leadership effectiveness. Leadership and Organization Development Journal 26(5):388-399.

Rost, J.C. 1993. Leadership for the twenty-first century. Westport, CT: Greenwood.

Ramchunder, Y. \& Martins, N. 2014. The role of self-efficacy, emotional intelligence and leadership style as attributes of leadership effectiveness: original research. SA Journal of Industrial Psychology 40(1):1-11.

Ruderman, M.N., Hannum, K., Leslie, J.B. \& Steed, J.L. 2001. Leadership skills andemotional intelligence (Unpublished manuscript). Greensboro, NC: Center for Creative Leadership.

Salovey, P. \& Mayer, J.D. 1990. Emotional intelligence. Imagination, Cognition and Personality 9:185-211.

Senge, P.M. 1997. Communities of leaders and learners. Harvard Business Review 75(5),30-32.

Spector, P.E. 2005. Introduction: emotional intelligence. Journal of organizational 
Behavior 26(4), 409-410.

StatSoft Inc. 2011. STATISTICA®.Version 10.0 [computer program]. Tulsa, OK: StatSoft.

Stein, S.J. \& Book, H.E. 2000. The EQ edge: emotional intelligence and your success. Mississauga, Ontario: Multi-Health Systems.

Stein, S.J.\& Book, H.E. 2006. The EQ edge: emotional intelligence and your success (revised \& updated). Mississauga, Ontario: Wiley.

Stuart, A. \& Paquet, A. 2001. Emotional intelligence as a determinant of leadership potential. Journal of Industrial Psychology 27(3):30-34.

Steiner, C. 1997. Achieving emotional literacy. London: Bloomsbury.

Struwig, H. 2012. personal communication on 18 November.

Tavakol, M. \& Dennik, R. (2011). Making sense of Cronbach's alpha. International Journal of Medical Education 2:53-55.

Thiry, K.J. 2009. Factors that affect peer rater accuracy in multi-rater feedback systems. Doctoral Dissertation. Minneapolis: Capella University.

Thorndike, E.L. 1920. A constant error in psychological ratings. Journal of Applied Psychology 4:25-29.

Van Oosten, E. B. 2013. The Impact of Emotional Intelligence and Executive Coaching on Leader Effectiveness. Doctoral dissertation. Ohio: Case Western Reserve University.

Veldsman, T.H. 2002. Into the people effectiveness arena: navigating between chaos and order. Randburg: Knowledge Resources.

Vrba, M. 2007. Emotional intelligence skills and leadership behaviour in a sample of South African first-line managers. Management Dynamics 16(2):25-35.

Welfens, P.J.J. 2009. Financial markets and instability: theory and policy issues. Heidelberg \& New York: Springer.

Welfens, P.J.J. 2011. From the transatlantic banking crisis to the euro crisis? International Economics and Economic Policy 8(1):15-29.

Wheatley, M. 1999. Leadership and the new science: discovering order in a chaotic world. San Francisco: Berrett-Koehler.

Wheatley, M. 2006. Leadership lessons from the real world. Leader to Leader 41:16. 
Woodruffe, C. 2001. Promotional intelligence. People Management 11(1):26-29. Available at: www.valuescentre.com (accessed on 30 July 2012).

Yukl, G. 1999. An evaluation of conceptual weaknesses in transformational and Charismatic leadership theories. The Leadership Quarterly, 10,285-305. Zeidner, M., Matthews, G. \& Roberts, R.D. 2004. Emotional intelligence in the workplace: a critical review. Applied Psychology: An International Review 53:371399. 